\title{
Fabrication of Yttria Stabilized Zirconia Thin Films on Porous Substrates for Fuel Cell Applications
}

\author{
by \\ Andrés Leming \\ B. S. (Stanford University) 1997 \\ A thesis submitted in partial satisfaction of the \\ requirements for the degree of \\ Master of Science \\ in \\ Engineering - Materials Science and Mineral Engineering \\ in the \\ GRADUATE DIVISION \\ of the \\ UNIVERSITY OF CALIFORNIA, BERKELEY \\ Committee in charge: \\ Professor Lutgard C. De Jonghe, Chair \\ Professor James W. Evans \\ Professor John S. Newman
}

Fall 2000 

LBNL-53450

\begin{abstract}
Fabrication of Yttria Stabilized Zirconia Thin Films on Porous Substrates

for Fuel Cell Applications

by

Andrés Leming

Master of Science in Materials Science and Engineering

University of California, Berkeley

Professor Lutgard C. De Jonghe, Chair
\end{abstract}

A process for the deposition of yttria stabilized zirconia (YSZ) films, on porous substrates, has been developed. These films have possible applications as electrolyte membranes in fuel cells. The films were deposited from colloidal suspensions through the vacuum infiltration technique. Films were deposited on both fully sintered and partially sintered substrates. A critical cracking thickness for the films was identified and strategies are presented to overcome this barrier. Green film density was also examined, and a method for improving green density by changing suspension $\mathrm{pH}$ and surfactant was developed. A dependence of film density on film thickness was observed, and materials interactions are suggested as a possible cause. Non-shorted YSZ films were obtained on co-fired substrates, and a cathode supported solid oxide fuel cell was constructed and characterized. 


\section{Dedication}

This thesis is dedicated to my family and to Francis Pham. 


\section{Table of Contents}

Chapter 1: Introduction

1.1 The Need for Fuel Cells

1.2 Historical Background

1.3 Fuel Cell Theory of Operation

1.4 Materials Requirements

1.5 Cell Structure

References

Chapter 2: Film Fabrication

2.1 Techniques

2.2 Vacuum Infiltration

2.3 Fabrication of Co-fired and Constrained Films

2.4 Stress in Co-fired and Constrained Films

2.5 Why Study Constrained Films

2.6 Common Factors

2.7 Experimental Methods

References

Chapter 3: Drying Cracks

3.1 Stress, Strength, and Cracking

3.2 Experimental Results

3.3 Calculations

3.4 Discussion

References

Chapter 4: Particle Packing and Density

4.1 Interparticle Forces

4.2 Experimental Results

4.3 Discussion

References

Chapter 5: Density and Film Thickness

5.1 Thinner Films Are Denser

5.2 Experimental Results

5.3 Discussion

References 
6.1 Co-fired Cells

6.2 Current/Voltage Characterization Techniques

6.3 Impedance Spectroscopy

6.4 Experimental Results

6.5 Discussion

References

Chapter 7: Conclusions

7.1 The Importance of an Integrated Approach

7.2 The Next Step 


\section{Acknowledgements}

First of all, I would like to thank Craig Jacobson. Our frequent interaction was the key to finishing this thesis. I would also like to thank Steve Visco for his role in shaping the research and all of his encouragement along the way. I would like to thank

Prof. De Jonghe for directing the research and for helping me to shape my thoughts into a coherent story. I am also indebted to Prof.'s Evans and Newman for taking the time to read this thesis and for making some very helpful comments.

I would also like to thank my fellow grad students (Abraham, Paul, Caroline, Mark, Tim, Emily, Peter, Yuriy). They have really been a pleasure to work with. In particular, Yuriy Matus was very helpful with the co-fired substrates and Gerardo Ola was instrumental in the experiments exploring the role of impurities in the system. And without the help of Abraham Anapolsky, this thesis would have taken another semester to complete.

I am also deeply grateful to Siemens-Westinghouse Power Corporation and the US Department of Energy for supporting this project. 


\section{Introduction}

\subsection{The Need for Fuel Cells}

Energy consumption in the US is on the rise. The Annual Energy Outlook 2000, published by the US department of Energy (DOE), projects an annual increase in energy consumption of 1.1 percent for the next twenty years from 27800 billion $\mathrm{kWh}$ in 1998 to 35200 billion $\mathrm{kWh}$ in 2020 . Electricity consumption is projected to grow by 1.4 percent annually from 3360 billion $\mathrm{kWh}$ in 2000 to 4350 billion $\mathrm{kWh}$ in $2020{ }^{1.1}$ As the need for clean and efficient energy sources becomes more apparent, fuel cells are emerging as viable alternatives for energy generation.

Fuel cells are a very clean and efficient way to generate electricity. Compared with current energy generation technologies, fuel cells have the potential of reducing $\mathrm{CO}_{2}$ emissions by $40-60 \%$ and $\mathrm{NO}_{\mathrm{x}}$ emissions by $50-90 \%{ }^{1.2}$ Solid oxide fuel cells exhibit electrical efficiencies well over 50\% and potential co-generation efficiencies of over $80 \%$. Co-generation describes the utilization of both the electrical and thermal energy produced by the cell (to drive a steam turbine for instance). For comparison, gas turbines, a common way of generating electricity, have efficiencies ranging from 40$50 \%$. Unlike gas and steam turbines, fuel cells do not suffer from efficiency losses when scaled down to smaller sizes. ${ }^{1.3}$ This makes them ideal for distributed power generation. 


\subsection{Historical Background}

Solid oxide fuel cells (SOFC's) have a long and distinguished history. Sir William Grove invented the fuel cell in 1839 , using sulfuric acid as the electrolyte. The first solid electrolyte (yttria stabilized zirconia) was discovered at the end of the nineteenth century by Nernst, while creating a device to replace the carbon filaments in electric lamps. This device was known as the Nernst glower. Schottky examined the theoretical aspects of solid electrolytes and suggested that the glower could be used as a fuel cell in 1935 . The first solid oxide fuel cell utilizing a ceramic electrolyte was built by Baur and Preis in 1937. It consisted of an yttria stabilized zirconia electrolyte and coke and iron oxide as the anode and cathode respectively. At $0.65 \mathrm{~V}$, it achieved about $0.3 \mathrm{~mA} / \mathrm{cm}^{2} .{ }^{1.4}$

Ceramic fuel cells sat in limbo until advances in stack design and ceramic processing caught up with theory. The first modern solid oxide fuel cells were built in the early 1960's. In 1962, Weissbart and Ruka at what was then Westinghouse Electric Corporation (now Siemens-Westinghouse Power Corporation), built a cell from a calcia stabilized zirconia electrolyte using two platinum electrodes and natural gas as a fuel. They achieved about $25 \mathrm{~mA} / \mathrm{cm}^{2}$ at $0.65 \mathrm{~V} .{ }^{1.5}$ Steady progress in the field has been made since then. More recently, researchers at the Lawrence Berkeley National Lab have achieved about $1500 \mathrm{~mA} / \mathrm{cm}^{2}$ at $0.65 \mathrm{~V}$ using yttria stabilized zirconia (YSZ) as an electrolyte, a nickel/YSZ anode, and a cathode made from lanthanum strontium manganate (LSM) ${ }^{1.6}$ The LBNL team used humidified hydrogen as a fuel.

Since the invention of the fuel cell, high production costs and the relative abundance of fossil fuels have worked against the adoption of commercial fuel cell 
technology. The most famous use of fuel cells was aboard the Gemini and Apollo space missions. ${ }^{1.7}$ These were alkaline fuel cells. The research described in this thesis is motivated by the desire to produce a thin ceramic film for use as an electrolyte in a solid oxide fuel cell (SOFC)

\subsection{Fuel Cell Theory of Operation}

A fuel cell consists of two electrodes (cathode and anode) separated by an electrolyte (figure 1.1). When hydrogen is fed to one side of the cell (anode) and oxygen is fed to the other side (cathode), an electrochemical potential is established. For the hydrogen/oxygen fuel cell shown, the potential is given by the Nernst equation:

$$
\mathrm{E}=\mathrm{E}_{0}+\frac{\mathrm{RT}}{2 F} \ln \left[\frac{\mathrm{P}_{\mathrm{H}_{2}}}{\mathrm{P}_{\mathrm{H}_{2} \mathrm{O}}}\right]+\frac{\mathrm{RT}}{2 F} \ln \left[\mathrm{P}_{\mathrm{O}_{2}}^{1 / 2}\right]
$$

where $\mathrm{E}$ is the potential obtained, $\mathrm{E}_{0}$ is the standard potential for the reaction, $\mathrm{R}$ is the gas constant, $\mathrm{T}$ is the temperature, $\mathrm{F}$ is Faraday's constant, $\mathrm{P}_{\mathrm{H}_{2}}$ is the partial pressure of hydrogen at the anode, $\mathrm{P}_{\mathrm{H}_{2} \mathrm{O}}$ is the partial pressure of water at the anode, and $\mathrm{P}_{\mathrm{O}_{2}}$ is the partial pressure of oxygen at the cathode.

This electrochemical potential causes charged ions to move from one side of the cell to the other through the electrolyte when an electrical load is applied. Ions flow in an attempt to reestablish the chemical potential at equilibrium. These ions are created by either oxidizing or reducing neutral species. This involves an exchange of electrons between the species and the electrode. By connecting both sides of the cell with an electronically conducting material, the ionic movement can be harnessed to extract 
electric power (see figure 1.1). In practice the hydrogen comes from such fuels as natural gas, and the oxygen is supplied from air. The fuel cell reaction product is primarily water. The main efficiency losses in fuel cells are due to resistive losses across the electrolyte, charge transfer overpotentials in the electrodes, and mass transfer overpotentials for the gaseous reactants.

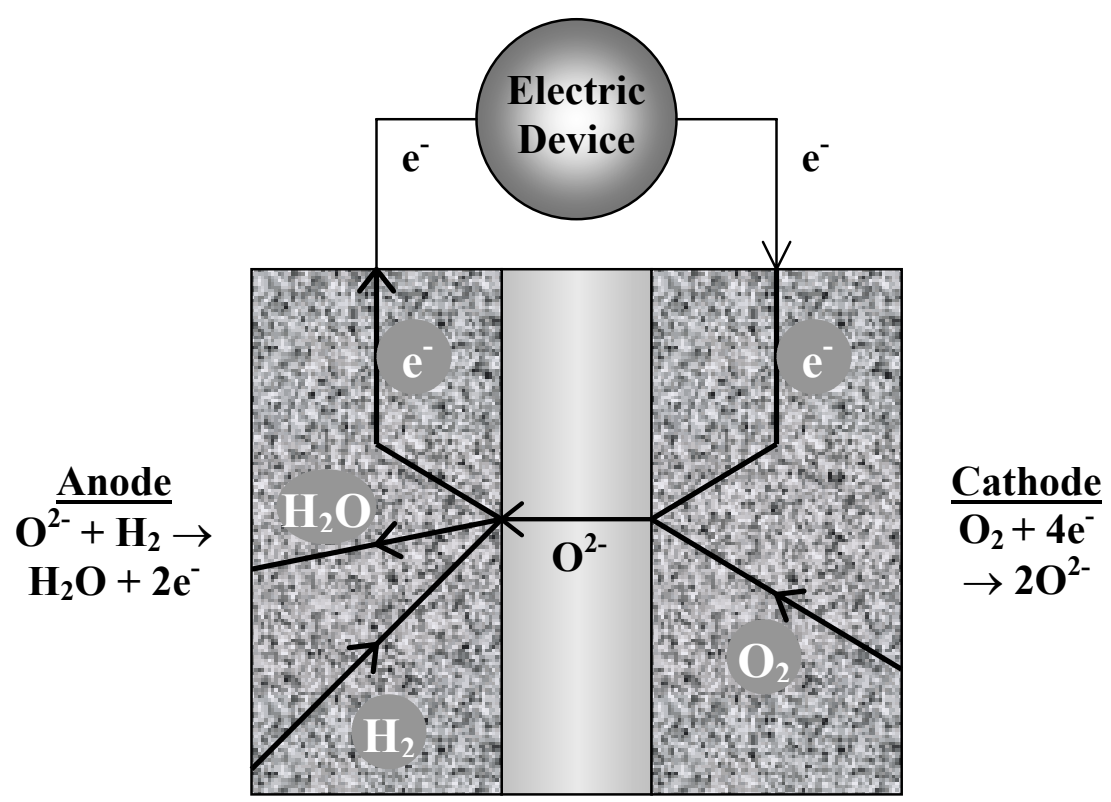

Figure 1.1 Fuel cell schematic

\subsection{Materials Requirements}

Fuel cell electrodes and electrolytes can be made from a variety of materials from ceramics to plastics. The solid oxide fuel cell (SOFC) is a ceramic fuel cell. One of the advantages of ceramic fuel cells is that almost any hydrocarbon can be utilized as fuel. The high operating temperatures (typically $800-1000^{\circ} \mathrm{C}$ ) allow internal reforming of the 
fuel to hydrogen and carbon dioxide. Additionally, the reaction between hydrogen and oxygen gives rise to high quality waste heat, which can be used to run steam turbines.

SOFC's are made from ceramics, metals, and ceramic-metal composites. The different parts of the fuel cell structure require different materials properties based on their differing functions. The fuel electrode (anode) must be porous, both electronically and ionically conductive, stable in reducing environment, and catalytic to the reaction that produces water. The air electrode (cathode) must be porous, both electronically and ionically conductive, stable in an oxidizing environment and catalytic to the dissociation of oxygen. The electrolyte must be dense, ionically conductive, and stable in both reducing and oxidizing environments. In addition, all of the materials must have similar thermal expansion characteristics and exhibit good chemical compatibility. ${ }^{1.4}$

The materials that we use for our fuel cells are yttria stabilized zirconia (YSZ) for the electrolyte, a mixture of nickel and YSZ for the anode, and a doped manganate for the cathode. We chose to use lanthanum strontium manganate (LSM) and lanthanum strontium calcium manganate (LSCM) at the cathode. The YSZ electrolyte is generally made as thin as possible to minimize efficiency losses due to the inherent resistivity of YSZ. Fuel cells made from these materials in similar configurations have shown excellent performance over long periods of time. Westinghouse has run cells made from these materials for over seven years with minimal material degradation in stacks of 25$100 \mathrm{~kW}$. They have also run them with a variety of fuels (natural gas to jet fuel). They estimate a commercial lifespan of $10-20$ years. ${ }^{1.8}$ This is an advantage compared to gas turbine systems, which must periodically be dismantled for service. 


\subsection{Cell Structure}

Combining fuel cells together into a "stack" allows us to achieve greater voltages and consequently greater power outputs. There are several different stack designs that have been developed over the years. The two most popular designs are the tubular and flat plate designs. Our efforts are primarily aimed at fabricating thin ceramic films for the tubular fuel cell stack design employed by Siemens-Westinghouse, although our techniques will also work well for flat plate cells. Individual tubular and planar stack components are shown in figures 1.2 and 1.3.

In the Siemens-Westinghouse tubular design, the oxygen electrode (cathode) acts as the structural support upon which the electrolyte film and the fuel electrode (anode) are applied. In the flat plate design, either electrode can serve as the structural support. The Siemens-Westinghouse cells are typically designed to run at $1000{ }^{\circ} \mathrm{C}$ for greater than 20,000 hours. To ensure the structural stability of the support over the lifetime of the cell, the cathode support tube is made from coarse LSCM powder fired at $1500{ }^{\circ} \mathrm{C}$. LSCM is a manganate compound $\left(\mathrm{Mn}_{2} \mathrm{O}_{3}\right)$ doped with lanthanum, strontium, and calcium. High sintering temperatures ensure stability but raise problems with the fabrication of the thin YSZ (yttria-stabilized zirconia) electrolyte layer. 


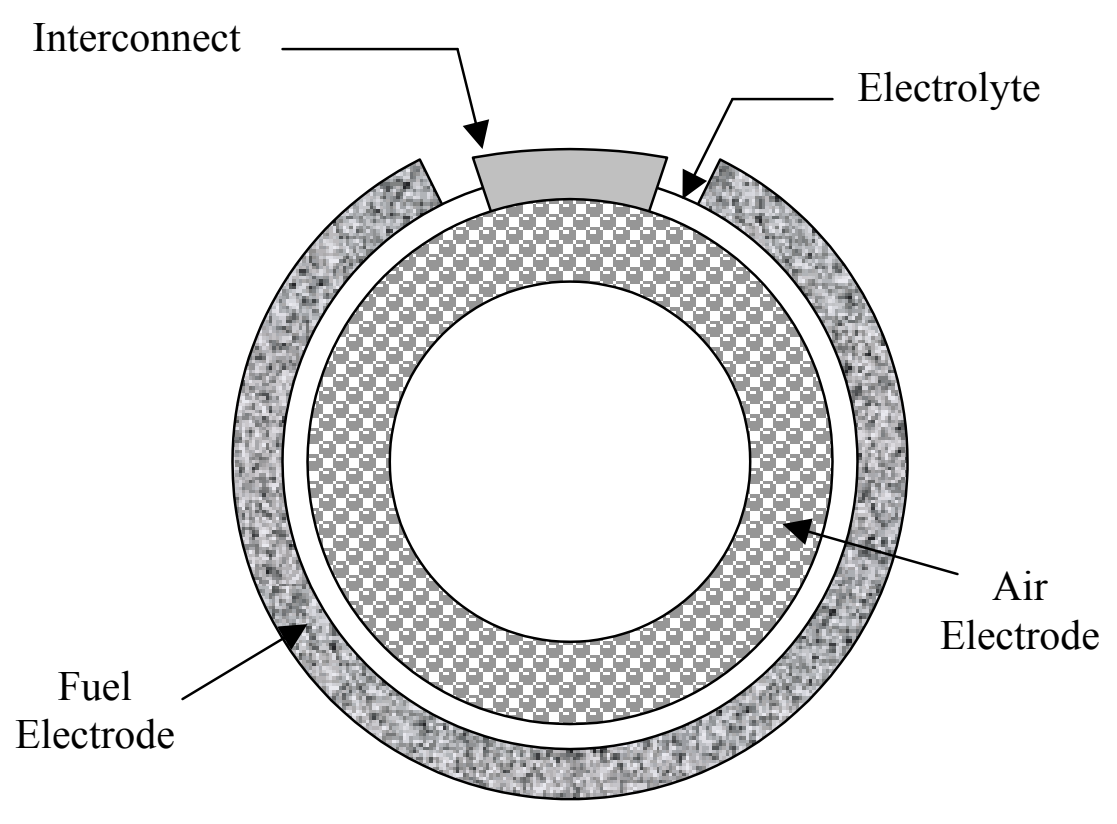

Figure 1.2 Siemens-Westinghouse tubular fuel cell design

In the next few chapters I discuss the fabrication of YSZ films on porous, rigid substrates and some of the important issues and variables to be considered in their fabrication. While the focus of this research is on rigid substrates, many of the same processing issues apply to co-fired substrates. In chapter 2 , I describe various methods by which thin YSZ films are applied and the method that we chose to employ. I also discuss some of the differences between co-fired and constrained sintering and why I have chosen to concentrate on constrained sintering. In chapter 3 , I discuss the significance of drying cracks in thin $(10-20 \mu \mathrm{m})$ films. Chapters 4 and 5 describe the effects of particle packing and film thickness on film density. In chapter 6 , impedance spectroscopy is discussed as a method of characterizing the films made. In chapter 7 the data and theory presented are summarized, and some conclusions are drawn. 


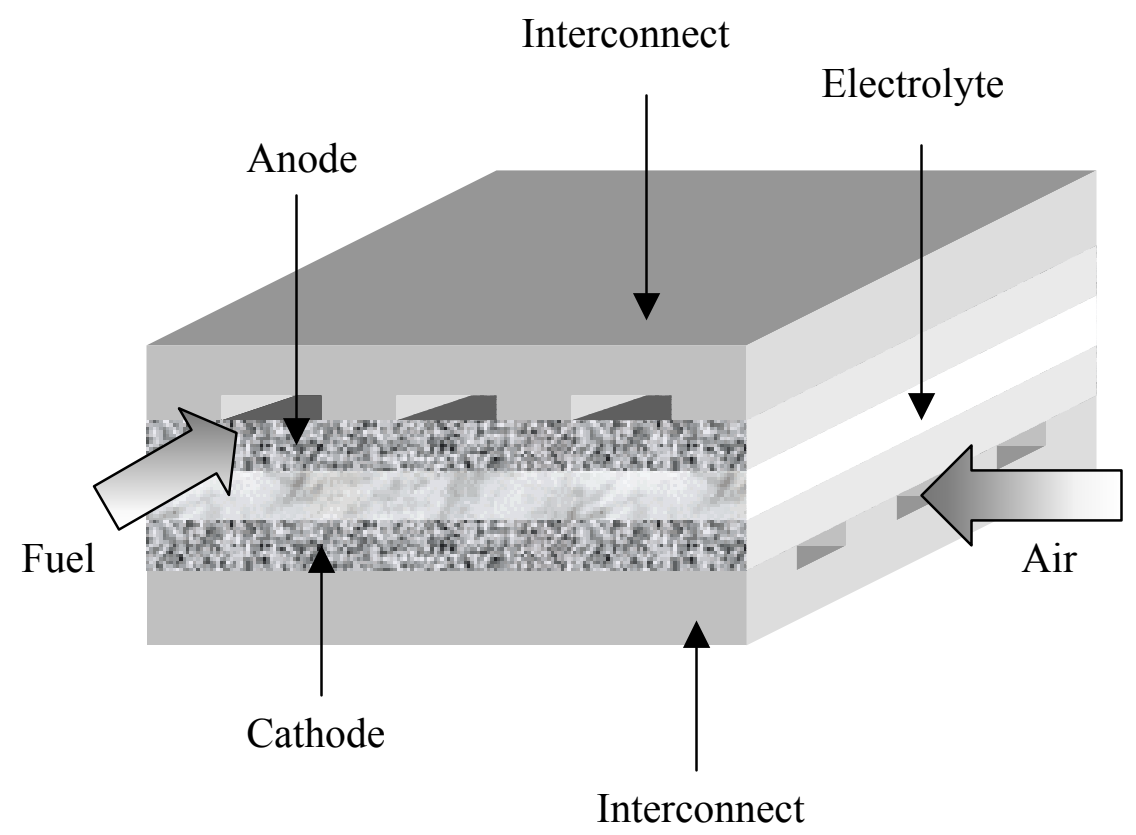

Figure 1.3 Flat plate design

\section{References}

[1.1] Annual Energy Outlook 2000 (AEO2000). Energy Information Administration (EIA) [Report\#:DOE/EIA-0383(2000)]

[1.2] Fuel Cells: Addressing Future Global Power Needs, Federal Energy Technologies Center (FETC). www.fetc.doe.gov. (1997).

[1.3] Khartchenko, Nikolai V. ed., Advanced Energy Systems. Taylor \& Francis (1998).

[1.4] Minh, N. Q. and Takahashi, T., Science and Technology of Ceramic Fuel Cells. Elsevier Science. 1995.

[1.5] Weissbart, J. and Ruka, R., A Solid Electrolyte Fuel Cell. Journal of the Electrochemical Society. 109 [8] pp 723-6. (1962). 
[1.6] de Souza, S., Visco, S., and De Jonghe, L., Reduced-temperature solid oxide fuel cell based on a YSZ thin electrolyte. Journal of the Electrochemical Society, 144 [3] p. L35-7 (1997).

[1.7] Service, Robert F., Bringing Fuel Cells Down to Earth, Science Magazine, vol. 285 (5428) p. 682. July 31, 1999.

[1.8] Fuel Cell Seminar Abstracts, November 16-19, 1998, Palm Springs, California, Mike Binder, "Status of US Stationary Power Plant Development," pg. 5-8. 


\section{Film Fabrication}

\section{$2.1 \quad$ Techniques}

Many methods exist for fabricating thin YSZ films on LSM or LSCM substrates.

Siemens-Westinghouse currently applies films by a two-step chemical and electrochemical vapor deposition process (CVD-EVD). During the first step of the process, the pores in the cathode substrate are filled with zirconia by a reaction between zirconium and yttrium chlorides and oxygenated steam. During the second step of the process, oxygen travels from the inside of the tube to the surface due to an oxygen activity gradient. The oxygen reacts with the chlorides to form the zirconia film. During this process, the zirconia is a mixed conductor and electrons flow in the opposite direction so as to preserve electroneutrality. This process takes place at approximately $1200^{\circ} \mathrm{C} .^{2.1}$ The CVD-EVD process produces very dense, high quality films, but is very expensive to implement and incorporates toxic chemicals.

Other film deposition methods have been attempted with varying degrees of

success. $^{2.2}$ Some of the most useful are sol-gel coating ${ }^{2.3}$, plasma spray ${ }^{2.4}$, and electrophoretic deposition of YSZ powder. ${ }^{2.5}$ Plasma spray coatings have the disadvantage of being somewhat porous and requiring a high temperature annealing step after deposition. They require the use of interlayers to stop the formation of insulating phases. Sol-gel films have the main disadvantage of being too thin. Multiple coatings 
are required in order to reach the required thickness. Electrophoretic films are promising but they also tend to be thin and exhibit pinholes, which can only be remedied by multiple deposition steps (5-7). What is really needed is a low cost, one step method of applying a dense YSZ film, which does not require high sintering temperatures.

\subsection{Vacuum Infiltration}

Vacuum infiltration is an excellent way of depositing thin ceramic films on porous tubes. This process is similar to pressure filtration except for the utilization of a pump to create a vacuum rather than a piston to create a pressure differential. YSZ powder is suspended in a liquid, and vacuum is applied to the inside of the porous object to be coated (figure 2.1). As the YSZ suspension is drawn through the substrate, powder is deposited on the outside surface (figure 2.2). This highly controllable technique allows us to achieve green films of high density ( $>55 \%)$ without resorting to further mechanical compaction methods. Varying either the suspension concentration or the amount of the suspension utilized for the infiltration controls film thickness. The kinetics of the process should be similar to those of pressure filtration. ${ }^{2.6}$ After deposition, the deposited films are sintered in a high temperature furnace. 


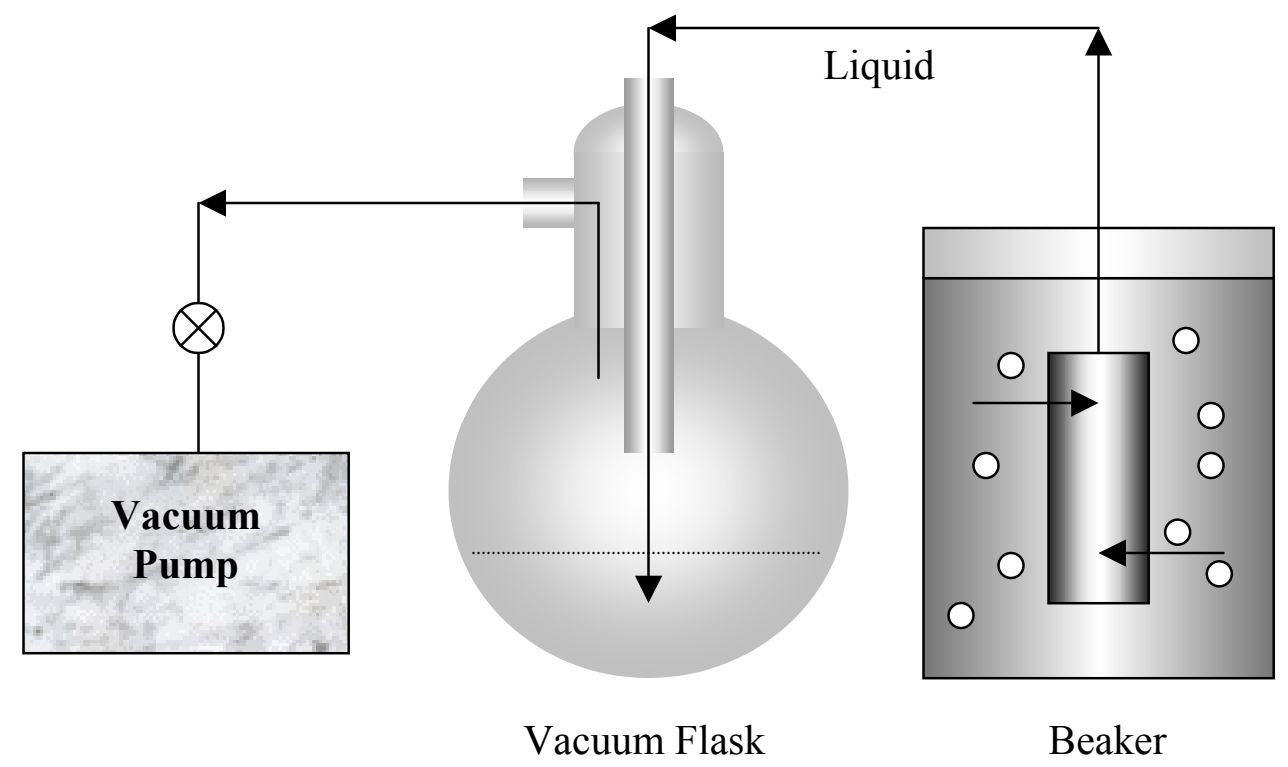

Figure 2.1 Vacuum filtration set-up

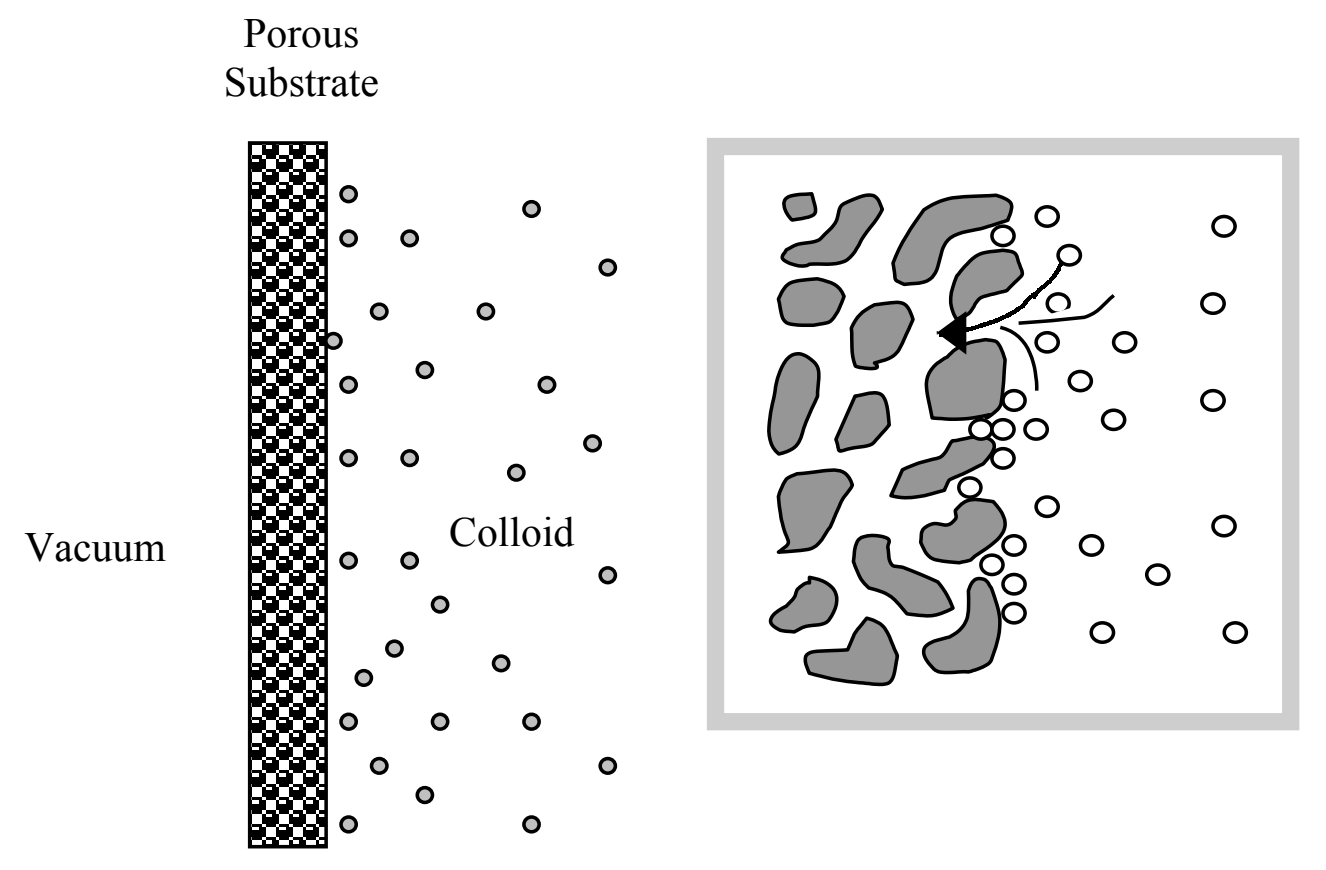

Figure 2.2 Close-up of the vacuum infiltration process 


\subsection{Fabrication of Co-fired and Constrained Films}

Vacuum infiltration can be utilized to produce thin YSZ films on both green (unsintered) and fully sintered ceramic substrates. The processing steps are slightly different, and different film densities result due to the different stress states experienced by the film during the sintering process.

Co-firing refers to a process in which the substrate and film are sintered simultaneously. A porous green body is made from the substrate material. It is pre-fired at roughly $2 / 3$ the sintering temperature to impart strength and burn out the carbon binder. The thin YSZ film is applied to the porous green body via vacuum infiltration or some other process. The film and substrate enter the furnace as one piece and are sintered together. The particle size, density, binder content, and shrinkage of the substrate and film are tailored so as to achieve a dense film and a porous substrate in the fully sintered state.

Constrained sintered films are fabricated in a similar manner but with a different firing sequence. The first step in the constrained sintering process is the production and sintering of the porous substrate. As opposed to the co-firing process, the substrate is completely sintered in this step and will retain its porosity and microstructure for the rest of the process. The green film is applied to the fully sintered substrate via vacuum infiltration or some other process. The substrate and film then go into the furnace and are sintered at a temperature below the sintering temperature of the substrate. The constraints in constrained sintering come from the attachment of the film to the substrate during the sintering process. This generally leads to lower film densities for constrained films, as discussed in the next section. 


\subsection{Stress in Co-fired and Constrained Films}

As a film sinters, it shrinks and becomes denser. Atomic diffusion is the cause of this shrinkage and densification. At elevated temperatures, forces are exerted on the green body by the diffusion of atoms from regions of high to low chemical potential. The forces created due to diffusion at pores and grain boundaries are often represented as an equivalent hydrostatic stress known as the sintering potential. Higher sintering potentials lead to faster densification rates. ${ }^{2.7}$

In the co-fired films shrinkage is not a problem since the substrate sinters and shrinks also. In the constrained case, stress arises in the plane of the film due to its attachment to the substrate. Strong bonding to the substrate does not allow shrinkage in the plane of the film. Consequently, the film is in tension along this plane and can only shrink in the direction normal to the film surface (figure 2.3).
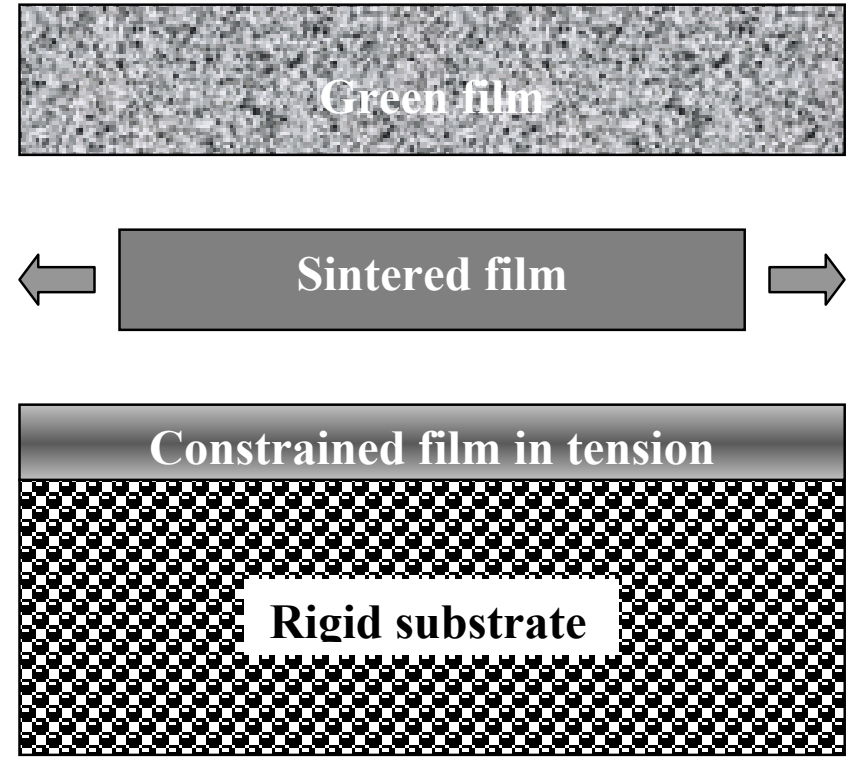

Figure 2.3 Constrained sintering 
Tension in the plane of the film leads to lower final densities in films that have been sintered under constraint. ${ }^{2.8}$ Due to the constraint, the sintering potential is effectively reduced to only a third of its original value. This accounts for some of the observed reduction in sintered density but not all. Choe et al. attribute the densification rate retardation to a change in the densification mechanism from "a faster grain-boundary diffusion dominated to that of a slower lattice diffusion dominated." ${ }^{2.9}$ This mechanism was also proposed by Bordia and Scherer. ${ }^{2.10}$ This mechanism has not been confirmed experimentally, however.

Much work has been done attempting to model stress in constrained films in a visco-elastic framework. Work done by Messing et al. measuring the elastic modulus of a sintering film, suggests that the sintering body is purely elastic during the initial stages of sintering and rapidly progresses to fully viscous behavior at elevated temperature. ${ }^{2.11}$ They also find that the peak sintering stress occurs just as the material begins to sinter and remains fairly constant during the sintering process. This observation was also made by Rahaman and De Jonghe. ${ }^{2.12}$

\subsection{Why Study Constrained Films}

The only working devices using vacuum infiltration thus far have been achieved with co-fired films. There are several reasons for this. The constraint imposed by the substrate retards the sintering of the constrained film. The constrained film is only allowed to densify in the direction normal to the plane of the film whereas the co-fired film is free to densify in all three dimensions. As a consequence, the sintering potential in constrained films can be up to $2 / 3$ less than that in the co-fired film. Co-fired films, on 
the other hand, can sinter to very close to full density, and excellent performance has been observed using co-fired devices.

So why look at constrained films at all? Even though they tend to be harder to densify, constrained films offer several advantages. Allowing the substrate to sinter separately from the film is a large advantage. This allows more control over substrate morphology. Substrates can be made from larger powders (generally cheaper) that sinter at very high temperatures, thereby ensuring the stability of the substrate microstructure. Yttria stabilized zirconia (YSZ) and lanthanum strontium manganate (LSM) form insulating reaction products $\left(\mathrm{SrZrO}_{3}\right.$ and $\left.\mathrm{La}_{2} \mathrm{Zr}_{2} \mathrm{O}_{7}\right)$ when fired simultaneously at high temperatures. This is unacceptable for an electrochemical device. Co-fired structures can also be subject to warping during sintering due to differences between film and substrate densification rates. This necessitates very tight controls over processing parameters. Warping is not a problem with constrained devices as the substrate is manufactured beforehand and generally has a homogenous microstructure.

\subsection{Common Factors}

While it is convenient to differentiate between co-fired films and films sintered under constraint, they actually share many common factors. Both processing routes involve the application of a green film, which must dry on an unyielding substrate. In both cases, maximum green density for the YSZ film is desired. When fired at high temperatures, both can react with the substrate materials. In reality the co-fired films are not completely free from constraints during sintering. If the substrate and film materials exhibit different sintering rates or start sintering at different temperatures, it is entirely 
likely that the co-fired film is subject to tensile or compressive stress during the sintering process. By focusing on the constrained case, we are not only exploring a potentially useful way of fabricating thin film structures, we are also investigating common processing factors in a more controlled environment which can serve to highlight effects not obvious in co-fired structures.

\subsection{Experimental Methods}

The yttria stabilized zirconia (YSZ) powder used for these experiments was obtained from TOSOH Corporation (TZ-8Y). The larger particle sizes were obtained by coarsening the TOSOH YSZ powder at $1200^{\circ} \mathrm{C}$, milling this powder for half an hour in an attritor mill, and settling out the large agglomerates in an isopropanol suspension. Powder size analysis was done on a HORIBA CAPA-700 particle size analyzer. Samples for particle size analysis were dispersed in water using Triton $\mathrm{X}$ as a dispersant.

YSZ suspensions were made at concentrations of 0.02 grams YSZ per liter of liquid. The suspensions were dispersed using a Branson Sonifier at 50\% output for 5 minutes. In the acid suspensions, enough $\mathrm{HCl}$ was added to achieve a $\mathrm{pH}$ of 2 . In the "salt" suspensions, 0.062 grams $\mathrm{ZrOCl}$ and 0.012 grams $\mathrm{YCl}$ were added to 50 milliliters water. Concentrations of $\mathrm{ZrOCl}$ and $\mathrm{YCl}$ were chosen so as to be proportional to the $\mathrm{Y}$ and $\mathrm{Zr}$ composition of the $\mathrm{YSZ}\left(8\right.$ at $\left.\% \mathrm{Y}_{2} \mathrm{O}_{3}\right)$. Acid or salt additions were made prior to the dispersion step.

The surfactant that we chose to use for these experiments is BRIJ $35-$ polyethylene glycol dodecyl ether $\left(\mathrm{C}_{12} \mathrm{H}_{25}-\mathrm{O}-\left[\mathrm{CH}_{2} \mathrm{CH}_{2}-\mathrm{O}\right]_{23}-\mathrm{H}\right) \mathrm{MW}=1198 \mathrm{~g} / \mathrm{mol}$. This is a commercially available compound (Fluka Chemika) available in various molecular 
weights. The BRIJ we chose is one of the shorter chain BRIJ molecules available and is soluble in water. The BRIJ surfactant was added to selected suspensions at a concentration of $0.307 \mathrm{~g} /$ liter (or $13 \mathrm{wt} \% \mathrm{YSZ}$ ). This concentration was found to exhibit good deposition properties experimentally. Films were deposited via the vacuum infiltration method described above using an Edwards RV5 vacuum pump.

Films were deposited on fully sintered porous tubes and partially sintered porous disks. The lanthanum strontium calcium manganate (LSCM) tubes were provided by Siemens-Westinghouse Power Corporation. The disks were made from a mixture of LSM and YSZ, using cornstarch as a pore former, and pre-fired at $1025^{\circ} \mathrm{C}$ for 8 hours. All deposited films were fired at $1400^{\circ} \mathrm{C}$ for 4 hours.

\section{References}

[2.1] Pal, U. B. and Singhal, S. C., Electrochemical Vapor Deposition of YttriaStabilized Zirconia Films, Proceedings of the First International Symposium on Solid Oxide Fuel Cells. Subhash C. Singhal ed., Electrochemical Society (1989).

[2.2] Minh, N. Q. and Takahashi, T., Science and Technology of Ceramic Fuel Cells. Elsevier Science. 1995.

[2.3] Kueper, T. W., Visco, S. J., and De Jonghe, L. C., Thin-film ceramic electrolytes deposited on porous and non-porous substrates by sol-gel techniques. Solid State Ionics 52 (1992) 251-259.

[2.4] Aihara, Y., Ito, S., and Kawasaki, S., Preparation of YSZ films on air electrodes by the thermal spray-sintering process. Proceedings of the Fourth International Symposium on Solid Oxide Fuel Cells (SOFC-IV), Pennington, NJ, USA: Electrochem. Soc, 1995. p.180-6.

[2.5] Ishihara, T., Sato, K., and Takita, Y., Electrophoretic Deposition of YO-Stabilized ZrO Electrolyte Films in Solid Oxide Fuel Cells. J. Am. Ceram. Soc. 79 (1996) 913-19.

[2.6] Lange, F. F., Powder Processing Science and Technology for Increased Reliability. J. Am. Ceram. Soc., 72 [1] 3-15 (1989). 
[2.7] Rahaman, M. N., Ceramic Processing and Sintering, Marcel Dekker, Inc. NY. 1995.

[2.8] Bang, J., and Lu, G-Q., Constrained Film Sintering of a Borosilicate Glass: In Situ Measurement of Film Stresses. J. Am. Ceram. Soc., 78 [3] 813-15 (1995).

[2.9] Choe, J. W., Calata, J. N., and Lu, G-Q., Constrained-film sintering of a gold circuit paste. J. Mater. Res., 10 [4] 986-994 (1995).

[2.10] Bordia, R. K., and Scherer, G. W. Ceram. Trans. 1 872-886 (1988).

[2.11] Cai, P. Z., Messing, G. L., and Green, D. L., Determination of the Mechanical Response of Sintering Compacts by Cyclic Loading Dilatometry. J. Am. Ceram. Soc., 80 [2] 445-52 (1997).

[2.12] Rahaman, M. N., De Jonghe, L. C., and Brook, R. J., Effect of Shear Stress on Sintering, J. Am. Ceram. Soc., 69 [1] 53-58 (1986). 


\section{Drying Cracks}

\subsection{Stress, Strength, and Cracking}

Cracks or flaws in a fuel cell's electrolyte film can seriously degrade device performance. Microscopic cracks in the electrolyte film can allow hot fuel and oxygen to meet. In the best case, this leads to performance losses. In the worst case, this leads to combustion and device failure.

When colloidal methods (i.e., vacuum infiltration) are used to fabricate ceramic films, device-threatening cracks can form as the film is dried. Drying solvent induces capillary stresses in the film. ${ }^{3.1}$ Due to constraints imposed by the substrate, stresses, which would normally be alleviated by green body shrinkage, grow (figure 3.1 ). When the drying stress exceeds the cohesive force of the green ceramic film, the film fractures (cracks). This process has been observed to occur primarily in films thicker than some critical cracking thickness (CCT), which is determined by a host of processing variables. ${ }^{3.2}$ Because the film is also under tension during sintering, cracks that are formed during drying will never close (figure 3.2). 

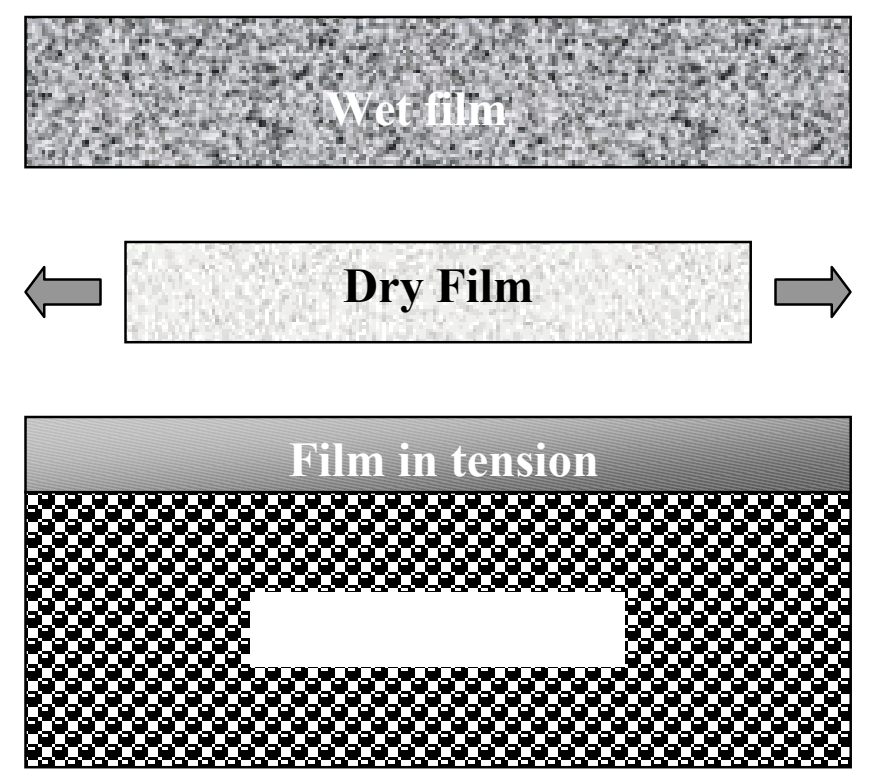

Figure 3.1 Drying stresses

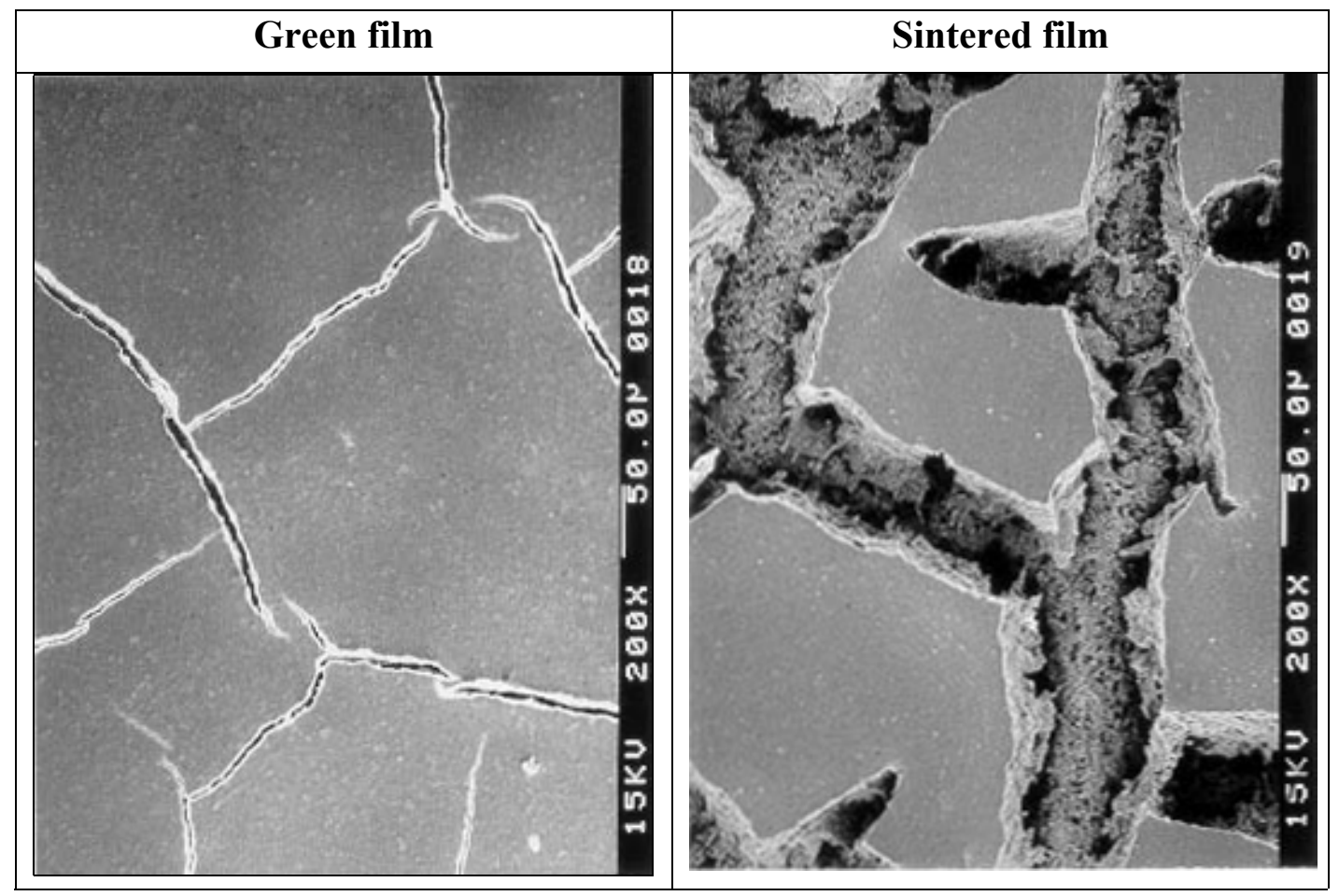

Figure 3.2 Effects of sintering stress on pre-existing flaws 
Predicting the occurrence of drying cracks necessitates knowledge of three primary parameters: drying stress, green strength, and film thickness. In the next section I present how certain processing variables affect critical cracking thickness (CCT), and in section 3.3 I describe how these processing variables relate to the three parameters necessary for predicting the CCT.

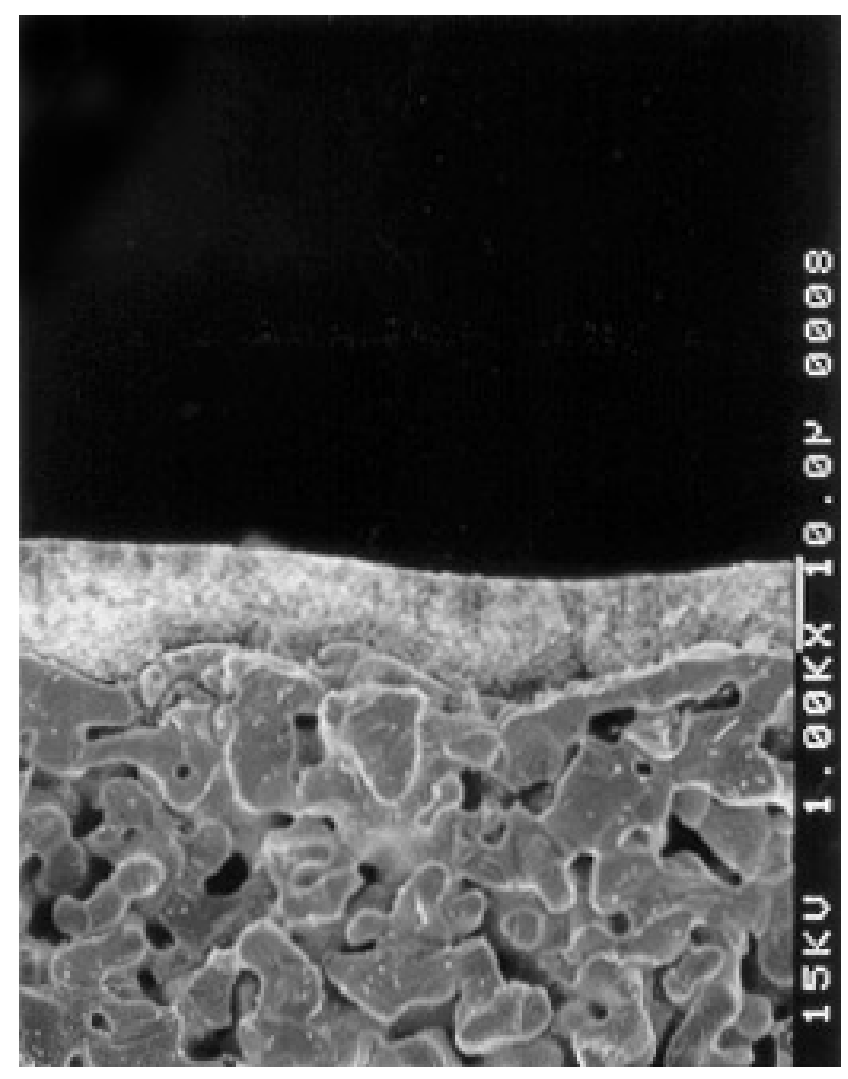

Figure 3.3 Green YSZ film on LSM substrate

\subsection{Experimental Results}

We explored the effects of particle size, surface tension, surfactants, and $\mathrm{pH}$ on the CCT of a vacuum infiltrated YSZ film on an LSCM substrate. Relevant experimental methods are described in sections 2.3 and 2.4. The minimum thickness chosen was $5 \mu \mathrm{m}$. 
It was impossible to obtain thinner films of uniform thickness due to the rough surface morphology of the tube (figure 3.3). Film thickness was varied in $5 \mu \mathrm{m}$ increments around the expected cracking thickness until the CCT was identified. Films thicker than $60 \mu \mathrm{m}$ are not particularly useful for fuel cell applications and were not examined. Most thin film fuel cell applications require ceramic films anywhere from 7-40 $\mu \mathrm{m}$ thick. The critical cracking thickness reported is based on pictures of green films taken in a scanning electron microscope (SEM) at magnifications of 500 to1000X. Cracking attributed to surface pits, inclusions, and tube morphology is not included. Results are summarized in figure 3.4.

\section{Critical Cracking Thickness}

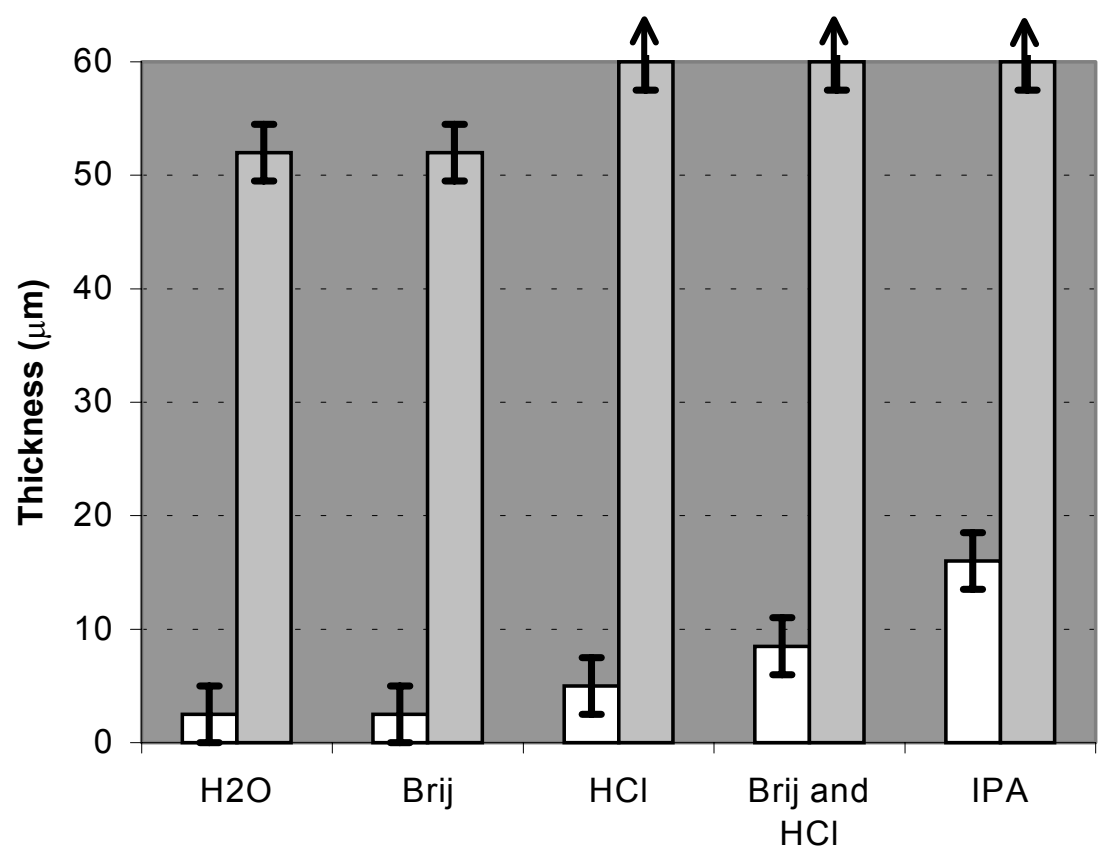

Figure 3.4 CCT for different deposition conditions 
Some examples of the types of film cracking possible are shown in figure 3.5. Figure 3.5 contains pictures of the surfaces and fracture edges of sintered films. All of the films in figure 3.5 were deposited from water suspension and would be approximately the same thickness $(20 \mu \mathrm{m})$ if they were not cracked. Note that the cracked films appear denser and thicker than the uncracked films. Although we believe that all of the cracking originated during drying, we can qualitatively determine the degree to which the sintering stress expanded the cracks during high temperature sintering. The long, connected cracks are indicative of extensive cracking during drying. The cracks with definite endpoints are indicative of drying cracks that have lengthened and expanded due to the sintering stress. The somewhat rounder, void-like cracks can most likely be attributed to holes in the film which expanded during sintering.

\subsubsection{Effects of surface tension and surfactant}

As expected, lower surface tensions led to greater critical cracking thicknesses (see section 3.3.1). Simple experiments were done measuring capillary rise to calculate surface tension. From those experiments (using $h=2 \gamma / \rho g r$, where $h$ is the height, $\gamma$ is the surface tension, $\rho$ is the density, $g$ is the acceleration due to gravity, and $r$ is the tube radius) we found the surface tensions of water, isopropanol (IPA) and water + Brij to be $0.072,0.021$, and $0.049 \mathrm{~J} / \mathrm{m}^{2}$ respectively. The values for water and isopropanol were found to be very close to the published values. The addition of acid was not observed to change the surface tension of the water solution. Although the Brij surfactant was found to lower the surface tension, it was not found to increase significantly the critical cracking thickness. 


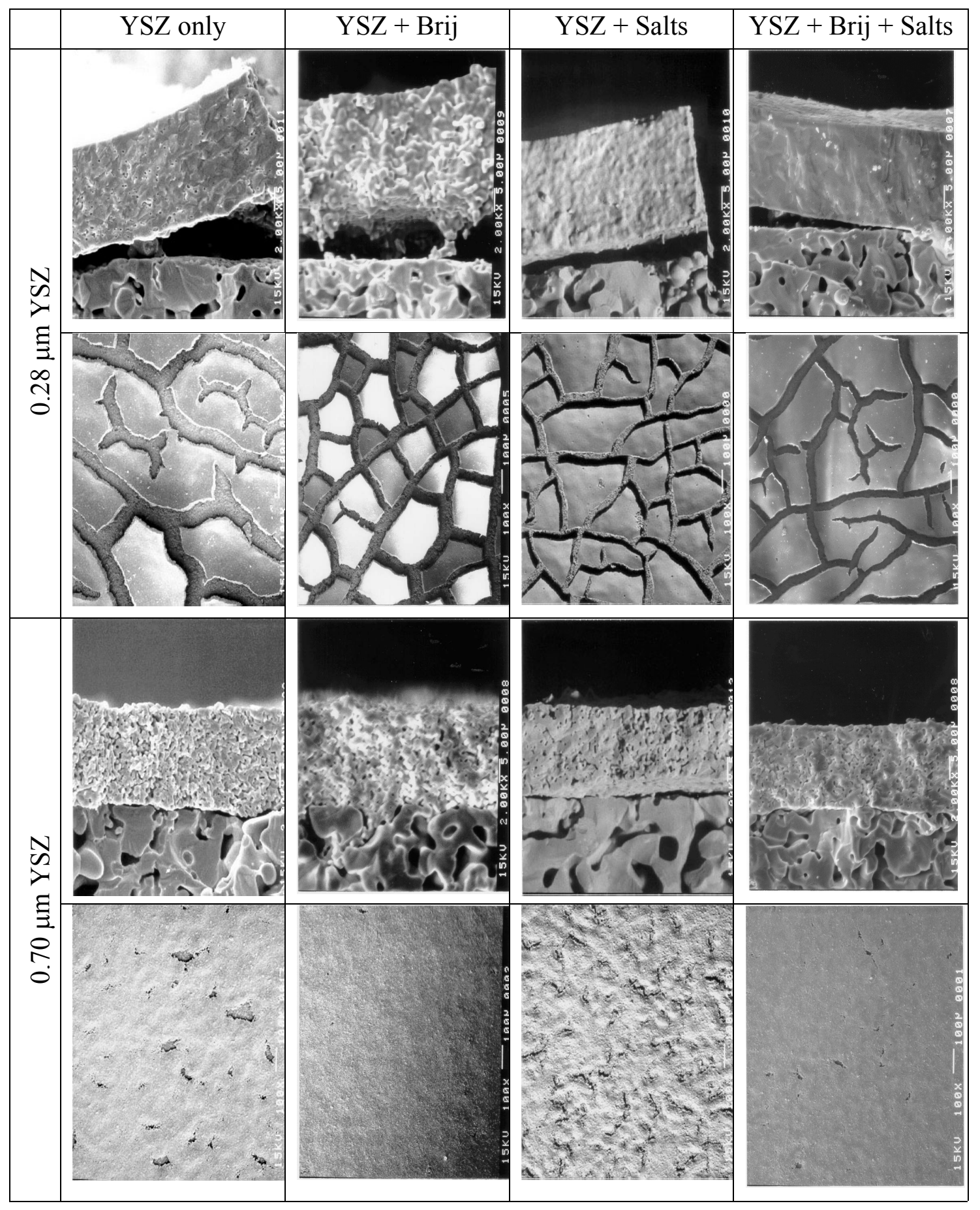

Figure 3.5 Types of cracks 


\subsubsection{Effects of Acid}

The acid was noticed to increase the critical cracking thickness of the films. Since the addition of acid did not significantly change the surface tension of the solution, we surmise that it must have made the green body stronger somehow. We attribute the increase in strength to greater green density on deposition (see section 4.2). Chiu et al. noticed a similar $\mathrm{pH}$ effect when alumina films were taken to $\mathrm{pH}<2 .{ }^{3.2}$ He attributed this increase in the critical cracking thickness to reprecipitation of alumina at particle necks. This type of effect should not occur in our films because zirconia is not nearly as soluble as alumina in $\mathrm{HCl}$ at these levels.

\subsubsection{Effects of Particle Size}

Particle size has the largest effect on the critical cracking thickness. A $0.42 \mu \mathrm{m}$ increase in particle diameter $(150 \%)$ leads to significant increases in critical cracking thickness. Chiu et al. noticed a very similar effect for alumina powders. ${ }^{3.2}$ They noticed that critical cracking thickness $\left(\mathrm{h}_{\mathrm{c}}\right)$ was directly proportional to the particle size. This also appears to be the case for our powders. The particle size distribution for each of our powders can be seen in figure 3.6. 
Particle Size Distributions

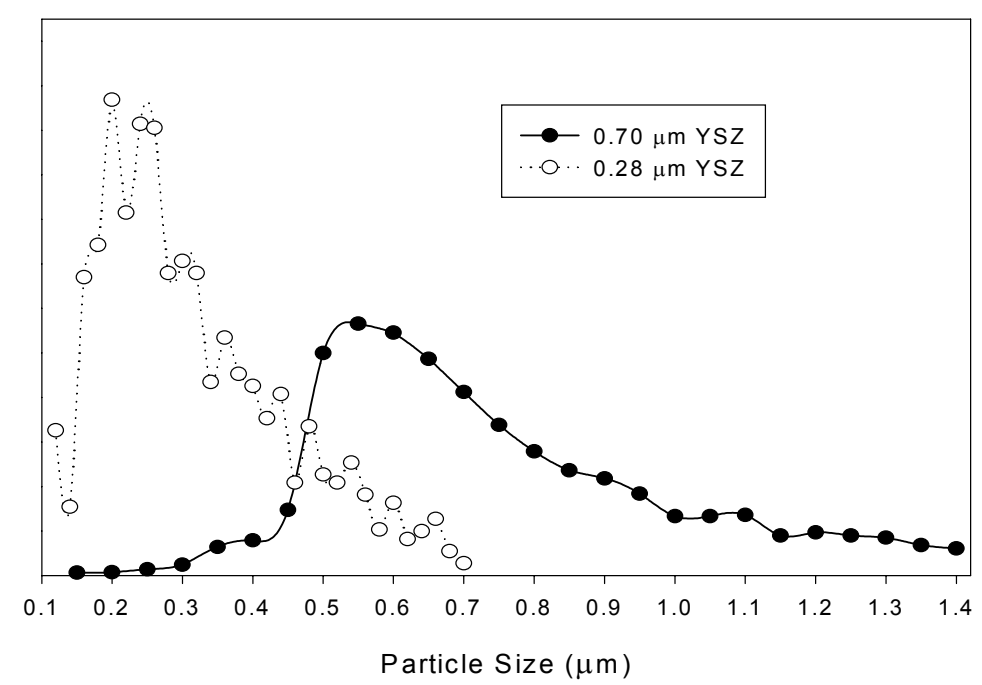

Figure 3.6 Particle Size Data

\subsection{Calculations}

\subsubsection{Drying Stresses}

When drying films are constrained by a rigid substrate, the peak drying stress controls the cracking characteristics. This peak stress occurs during what is called the "falling rate period" when the drying front just enters the powder compact. ${ }^{3.1}$ The stress falls off relatively rapidly after this point. ${ }^{3.5}$

Various methods have been employed to calculate drying stresses in ceramic films. A common expression used to describe the drying stresses in bulk ceramics is

$$
\sigma=2 \gamma_{\mathrm{LV}} \cos \theta / \mathrm{a}
$$


where $\sigma$ is the stress in the film, $\gamma_{\mathrm{LV}}$ is the surface tension of the liquid vapor interface, $\theta$ is the contact angle between the liquid and the solid ceramic, and a is the pore radius. ${ }^{3.3}$ Bellet and Canham use this expression, with the contact angle set equal to zero, to determine the drying stresses in thin porous silicon films. ${ }^{3.4}$ When considering ceramic green bodies, using geometric arguments for the packing of spheres, we can approximate the radii of the pores as roughly half the radii of the particles, $r$. Scherer developed an expression to calculate stresses in sol-gel films and found that:

$$
\sigma=\gamma_{\mathrm{LV}} \cos \theta \mathrm{S} \rho_{\mathrm{s}} \rho /(1-\rho)
$$

where $\mathrm{S}$ is the specific surface area of the porous body (we assume that this is the same as the powder), $\rho_{\mathrm{s}}$ is the density of the bulk material, and $\rho$ is the green density of the porous body. ${ }^{3.1}$ To find the specific surface area of the powder using geometric arguments, we could use the following equations: $\mathrm{V}_{\text {sphere }}=(4 / 3) \pi \mathrm{r}^{3}, \mathrm{SA}_{\text {sphere }}=4 \pi \mathrm{r}^{2}$, $\mathrm{S}=3 / \mathrm{r} \rho$. Chiu and Cima used an expression taken from soil science to calculate drying stress:

$$
\sigma=2 \phi \gamma_{\mathrm{LV}} / \mathrm{d}
$$

where $\phi$ is a packing factor $(\sim 8)$ and $\mathrm{d}$ is the diameter of the particle. ${ }^{3.5}$

We used the methods described above to calculate drying stresses in our films for the two different sized particles in water and isopropanol (IPA). We first assumed that the density of the green body did not vary with particle size ( $\sim 60 \%$ for all films) and used $\gamma_{\mathrm{LV}}=0.072 \mathrm{~J} / \mathrm{m}^{2}$ for water, $0.021 \mathrm{~J} / \mathrm{m}^{2}$ for IPA, and $\theta=\sim 50^{\circ}$ for water, $\sim 5^{\circ}$ for IPA. Contact angles are based on visual observations of droplets on polished YSZ disks. For YSZ with a density of $5.9 \mathrm{~g} / \mathrm{cm}^{3}$, the specific surface area (S) comes out to $3.63 \mathrm{~m}^{2} / \mathrm{g}$ for 
the $0.28 \mu \mathrm{m} \mathrm{YSZ} \mathrm{powder} \mathrm{and} 1.45 \mathrm{~m}^{2} / \mathrm{g}$ for the $0.70 \mu \mathrm{m} \mathrm{YSZ}$ powder. The results of these calculations appear in table 3.1. The different methods come out with very similar results (within a factor of 3 or better) for the drying stress.

\begin{tabular}{|c|c|c|}
\hline \multicolumn{3}{|c|}{ Table 3.1 Drying Stress } \\
\hline & Isopropanol & Water \\
\hline \multicolumn{3}{|l|}{ Bulk } \\
\hline $0.28 \mu \mathrm{m}$ YSZ powder & $0.60 \mathrm{MPa}$ & $1.32 \mathrm{Mpa}$ \\
\hline $0.70 \mu \mathrm{m}$ YSZ powder & $0.24 \mathrm{MPa}$ & $0.53 \mathrm{Mpa}$ \\
\hline \multicolumn{3}{|l|}{ Scherer } \\
\hline $0.28 \mu \mathrm{m}$ YSZ powder & $0.67 \mathrm{MPa}$ & $1.49 \mathrm{Mpa}$ \\
\hline $0.70 \mu \mathrm{m}$ YSZ powder & $0.27 \mathrm{MPa}$ & $0.59 \mathrm{Mpa}$ \\
\hline \multicolumn{3}{|l|}{ Chiu and Cima } \\
\hline $0.28 \mu \mathrm{m}$ YSZ powder & $1.2 \mathrm{MPa}$ & $4.11 \mathrm{Mpa}$ \\
\hline $0.70 \mu \mathrm{m}$ YSZ powder & $0.48 \mathrm{MPa}$ & $1.65 \mathrm{Mpa}$ \\
\hline
\end{tabular}

\subsubsection{Film Strength and Critical Cracking Thickness}

Having calculated the drying stress, the next variable we need to predict film failure is the strength or fracture toughness of the film, $\mathrm{K}_{\mathrm{Ic}}$. To calculate this parameter and determine its effect on the critical cracking thickness, we envision the cracking process as occurring in two steps. The first step deals with the formation of a throughthickness crack, and the second step involves the propagation of that crack along the film.

The through-thickness crack can occur for a variety of reasons. The deposited powder may exhibit through-thickness micro-cracks from the very beginning. Problems with the deposition process may lead to areas of the film being thicker or thinner than the average. This could lead to stress concentrations in the thin regions. Inhomogeneous 
deposition could also lead to stress concentrations in regions of lower density, thereby forming "effective cracks" (figure 3.7). It is also possible for large agglomerates in the substrate to inhibit powder deposition in the regions immediately above them.

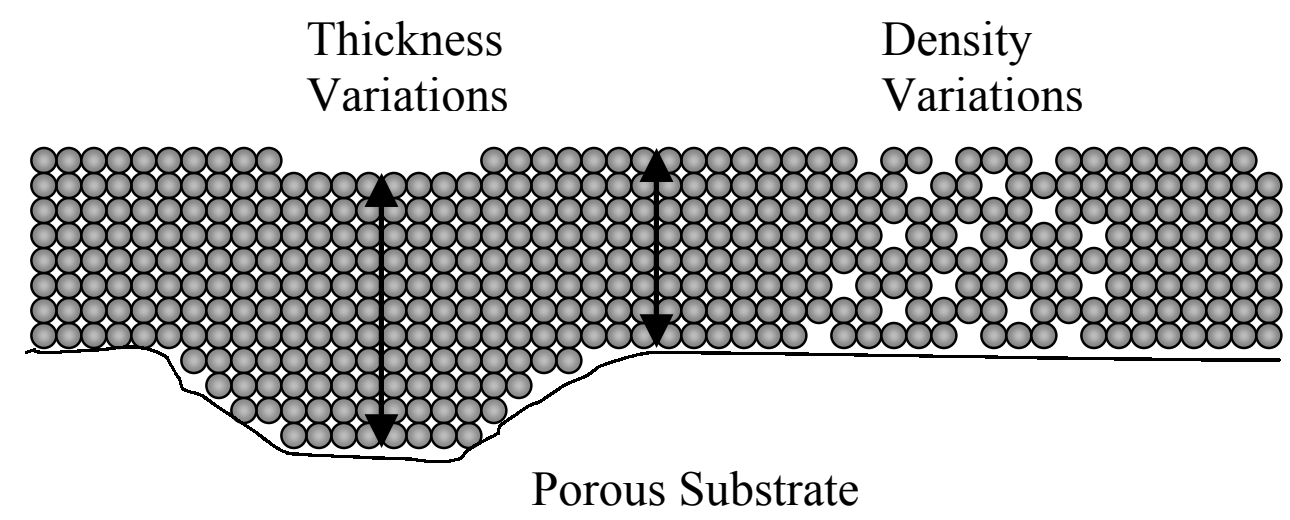

Figure 3.7 Effective cracks

While it is difficult to formulate expressions for through thickness cracking due to thickness or density inhomogeneities, the equations for the through-thickness propagation of surface cracks are well known. ${ }^{3.6}$

$$
1.2 \pi \sigma^{2} \mathrm{c}>\mathrm{EG}_{\mathrm{f}}
$$

where $\sigma$ is the drying stress, $\mathrm{c}$ is the depth of a flaw, $\mathrm{E}$ is the elastic modulus of the film (assumed equal to that of the substrate), and $\mathrm{G}_{\mathrm{f}}$ is the critical strain energy release rate for crack extension (equal to twice the surface energy).

Once the crack has penetrated to the film/substrate interface, it propagates along the plane of the film. For propagation of the crack along the film, surface energy 
arguments are commonly used. Based on work done by Hu et al., the critical cracking thickness can be derived from:

$$
\mathrm{h}_{\mathrm{c}}=\mathrm{EG}_{\mathrm{f}} / 0.6 \pi \sigma^{2} \text { or } \mathrm{h}_{\mathrm{c}}=\left(\mathrm{K}_{\mathrm{Ic}} / 1.4 \sigma\right)^{2}
$$

where $h_{c}$ is the critical cracking thickness and $\mathrm{K}_{\mathrm{Ic}}=(\mathrm{EG})^{1 / 2.2 .1,3.6,3.7}$ This analysis assumes that the film and substrate have the same elastic properties and the film is well adhered. If we compare the strain energy release rates for through thickness cracks and cracks along the film, we can see that a given flaw will propagate down into the film before it will propagate along the film.
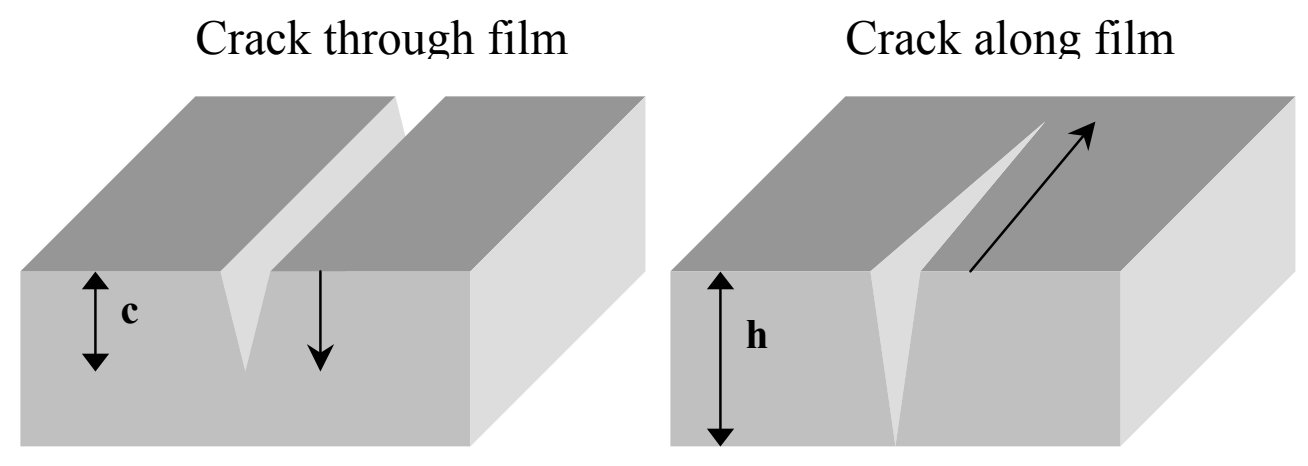

Figure 3.8 Two types of cracking

In order to calculate $\mathrm{h}_{\mathrm{c}}$, we need to know either, $\mathrm{E}$ and $\mathrm{G}_{\mathrm{f}}$, or $\mathrm{K}_{\mathrm{c}}$. We can calculate the fracture toughness of the green body using a formulation derived by Kendall:

$$
\begin{gathered}
\mathrm{E}^{*}=17(1-\varepsilon)^{4}\left(\mathrm{E}^{2} \Gamma / \mathrm{d}\right)^{1 / 3} \\
\mathrm{G}^{*}=56(1-\varepsilon)^{4}\left(\Gamma_{\mathrm{c}}^{5} / \mathrm{E}^{2} \mathrm{~d}^{2}\right)^{1 / 3} \\
\mathrm{~K}_{\mathrm{Ic}}=\left(\mathrm{E}^{*} \mathrm{G}^{*}\right)^{1 / 2}=31(1-\varepsilon)^{4} \Gamma_{\mathrm{c}}^{5 / 6} \Gamma^{1 / 6} \mathrm{~d}^{-1 / 2}
\end{gathered}
$$


where $\Gamma$ is the interface energy of the solid, $\Gamma_{\mathrm{c}}$ is the fracture surface energy, and $\mathrm{E}$ is the Young's modulus of the solid. In theory, $\Gamma$ is equal to twice the surface energy, $\gamma,(\Gamma=2$ $\mathrm{J} / \mathrm{m}^{2}$ for zirconia). In practice, Kendall found $\Gamma$ to be $0.3 \mathrm{~J} / \mathrm{m}^{2}$ for zirconia in his experiments and attributed this disparity to surface impurities. ${ }^{3.8}$ The $\Gamma_{\mathrm{c}}$ term contains energy spent in plastic deformation and heat dissipation and is therefore not equal to $\Gamma$. Kendall found experimental $\Gamma_{\mathrm{c}}$ values for alumina and titania (21 and $14 \mathrm{~J} / \mathrm{m}^{2}$, respectively) but not for zirconia. ${ }^{3.9}$

Bellet et al. used a very different equation for determining the critical cracking thickness in porous silicon. ${ }^{3.4,3.10}$ They set the elastic energy, $\sigma^{2} h_{c} /\left(2 E_{P}\right)$, equal to the energy required to break the interface (twice the surface energy), 2(1-p) $\gamma_{\mathrm{B}}$. They then solved for the cracking thickness and utilized $\mathrm{E}_{\mathrm{P}}=\mathrm{E}_{\mathrm{B}}(1-\mathrm{P})$ to get:

$$
h_{c}=4 E_{B}(1-P)^{3} \gamma_{L V} / \sigma^{2}
$$

where $E_{B}$ is the elastic modulus of the bulk material and $E_{P}$ is the elastic modulus of the porous material. Bellet et al. get good agreement with experimental results using this expression.

\subsection{Discussion}

The calculation of critical cracking thickness is not useful for quantitative predictions. We would like to predict critical cracking thickness to within $5 \mu \mathrm{m}$. Because Hu's equation for critical cracking thickness relies on the square of the fracture toughness $\left(\mathrm{K}_{\mathrm{Ic}}\right)$ divided by the drying stress $(\sigma)$, these values must be extremely accurate to obtain reasonable values for the critical cracking thickness $\left(h_{c}\right)$. It appears that it is possible to get reasonable values for the drying stress through a variety of methods 
(section 3.3.1). However, it is much more difficult to obtain good values for the fracture toughness.

Fracture toughness values exhibit a strong dependence on interparticle adhesion. The strength of these forces is determined by processing variables which include: solvent, packing density, and use of surfactants. ${ }^{3.9}$ It appears that large differences in fracture toughness exist between particle compacts that are slip cast versus those that are die pressed. ${ }^{3.11}$ We attribute the increase in critical cracking thickness due to the acid addition to the consequent increase in packing density (see section 4.2). The strength of interparticle forces in the green body becomes difficult to predict and must be experimentally determined for most systems. This is a problem with any formulation of fracture toughness and any critical cracking thickness determination that requires the particle to particle strength such as that of Bellet et al.

While the calculation of quantitative values of the critical cracking thickness may not be possible, it appears that various trends in the data could be very useful. Chiu et al. observed that the critical cracking thickness for their films exhibited the correct linear dependence on particle size predicted by using the formulations of $\mathrm{Hu}$ and Kendall. They also observed a linear relationship between critical cracking thickness and the Hamaker constant for silica and alumina $\left(8.8 \times 10^{-20}\right.$ and $\left.15.6 \times 10^{-20} \mathrm{~J}\right){ }^{3.2,3.5}$ The Hamaker constant for ceramics is related to their surface energy, which has been experimentally determined to be 0.3 and $0.58 \mathrm{~J} / \mathrm{m}^{2}$ for zirconia and alumina respectively. ${ }^{3.8}$ A plot of our data and Chiu's for films deposited from aqueous solutions, without additives, appears below (figure 3.9). A linear curve fit was applied to the alumina data. This is the black line on 
the graph. The white line corresponds to that curve fit scaled by the ratio of the surface energies for alumina and zirconia.

Our limited data do not fall directly on this curve, but they come reasonably close. Note that Chiu et al. refer to green thickness and we refer to sintered thickness when discussing critical cracking thickness. Our values have been multiplied by a factor of two (observed thickness change upon sintering) to compare them with Chiu et al.'s. It appears that more data are required to determine the exact relationship between surface energy and critical film thickness in our films.

\section{Cracking Thickness vs. Particle Size}

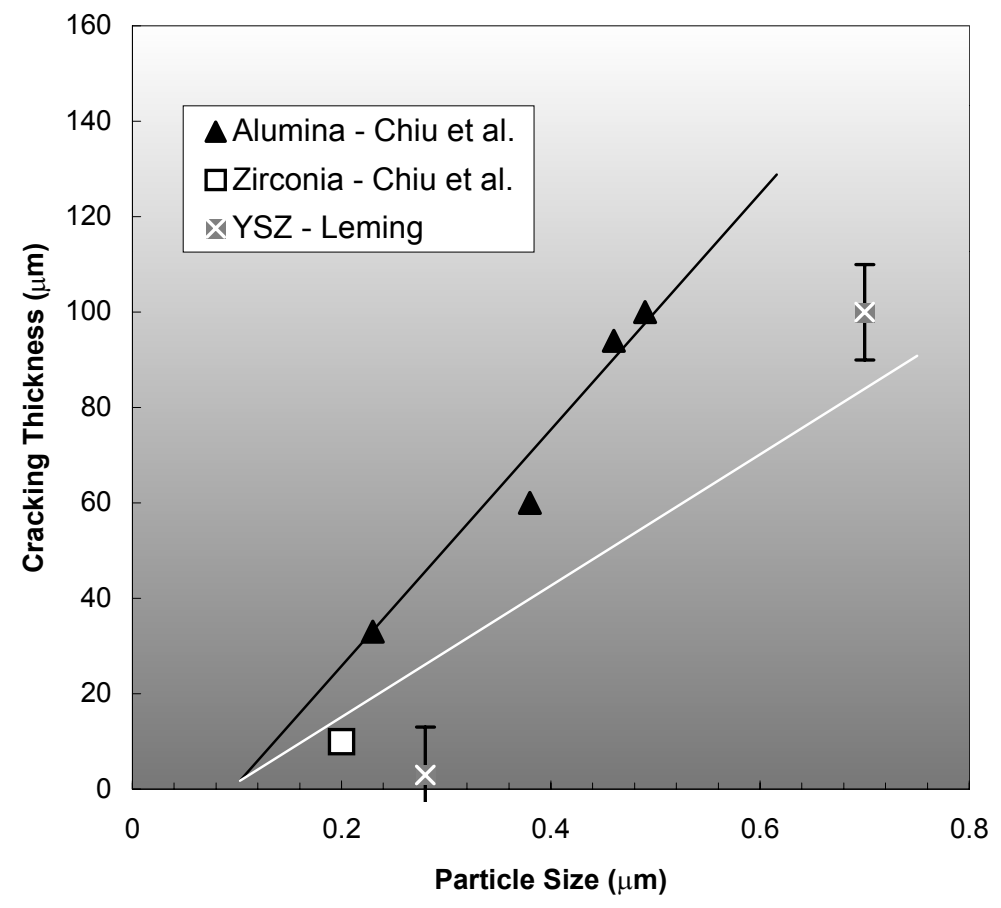

Figure 3.9 Plot of CCT versus particle size 
Our data were obtained for films deposited via vacuum infiltration on porous substrates as opposed to Chiu et al.'s which were obtained from films cast on glass plates. But if it can be shown that critical cracking thickness exhibits a linear dependence on particle size, which scales with surface energy, this could be very useful information. Having one set of data for a system (i.e., alumina) would allow us to find the critical cracking thickness for other systems (processed in a similar manner) by scaling them with their Hamaker constants or surface energies.

From the above discussion, we see some obvious ways of controlling processing variables to achieve thicker films. We can lower the drying stresses by utilizing solvents with lower surface tensions or increasing the pore/particle size. It may even be possible to change the solvent contact angle through some surface treatment of the powder particles. Alternatively, we can strengthen the green film to increase $\mathrm{K}_{\text {Ic }}$ by changing the processing variables and additives.

Eliminating drying cracks is not the end of the story, however. It is also possible for films to crack due to sintering rather than drying stresses. The theoretical treatment of these stresses and related critical thickness is very similar to that for drying stresses. We originally explored the possibility of sintering induced cracks but realized that almost all of our film flaws could be directly related to flaws in the green films. The sintering stresses only appear to play a role in magnifying existing flaws and not in their production. 


\section{References}

[3.1] Scherer, G. W., Theory of Drying, J. Am. Ceram. Soc., 73 [1] 3-14 (1990).

[3.2] Chiu, R. C., Garino, T. J., and Cima, M. J., Drying of Granular Films: I, Effect of Processing Variables on Cracking Behavior, J. Am. Ceram. Soc., 76 [9] 2257-64 (1993).

[3.3] Rahaman, M. N., Ceramic Processing and Sintering, Marcel Dekker, Inc. NY. 1995.

[3.4] Bellet, D. and Canham, L., Controlled Drying: The Key to Better Quality Porous Semiconductors, Adv. Mater., 10 [6] 487-490 (1998).

[3.5] Chiu, R. C., and Cima, M. J., Drying of Granular Ceramic Films: II, Drying Stress and Saturation Uniformity, J. Am. Ceram. Soc., 76 [11] 2769-77 (1993).

[3.6] Atkinson, A. and Guppy, R. M., Mechanical Stability of Sol-Gel Films, J. Mat. Sci. 26 [14] 3869-3873 (1991).

[3.7] Hu, M. S., Thouless, M. D., and Evans, A. G., The Decohesion of Thin Films from Brittle Substrates, Acta. Metall. 36 [5] 1301-1307 (1988)

[3.8] Kendall, K., Alford, N. McN., and Birchall, J. D., Elasticity of particle assemblies as a measure of the surface energy of solids, Proc. R. Soc. Lond. A 412, 269-283 (1987).

[3.9] Kendall, K., Agglomerate Strength, Powder Metallurgy, 31 [1] 28-31 (1998).

[3.10] Belmont, O., Bellet, D., and Brechet, Y., Study of the cracking of highly porous p+ type silicon during drying, J. Appl. Phys., 79 [10] 15 May 1996.

[3.11] Bortzmeyer, D., Langguth, G., and Orange, G., Fracture Mechanics of Green Products, J. Eur. Ceram. Soc., 11 [1] 9-16 (1993). 


\section{Particle Packing and Density}

\subsection{Interparticle forces}

As expected, the green density of the film directly impacts its final sintered density. Consequently, the next step after making the films crack-free is making them dense. Forces between particles (attractive and repulsive) affect green density. Therefore, to achieve dense films, we must be able to exert some control over interparticle forces.

Interparticle behavior is governed by a balance between van der Waals, electrostatic, and steric forces. Attractive van der Waals forces exist between all particles due the interaction of the particles' electron clouds. In the absence of other forces, the van der Waals force can lead to flocculation. This is generally deleterious to green body formation, and we can manipulate repulsive electrostatic and steric forces to counteract this attractive force.

When a ceramic powder is suspended in a liquid, the particle surface interacts with the solvent and becomes hydrated. In aqueous solutions, this results in the formation of hydroxide $(\mathrm{OH})$ groups on the particle surface. These groups form a thin charged layer on the particle surface surrounded by a diffuse, oppositely charged layer. These two layers together are known as the electrostatic double layer. In order to enhance this double layer, it is possible to react an acid $(\mathrm{H}+)$ or base $(\mathrm{OH}-)$ with the 
hydroxide groups on the particle surface, thereby increasing the electrostatic charge on the particles (figure 4.1). ${ }^{4.1}$ In addition, all powder/liquid systems have some $\mathrm{pH}$ value known as the "point of zero charge" (PZC) or isoelectric point (IEP) where the particle surface is electrically neutral. ${ }^{4.2}$

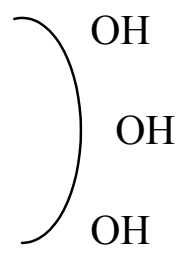

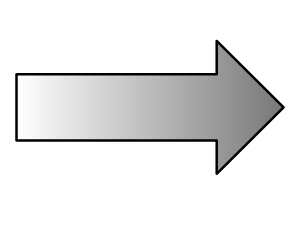

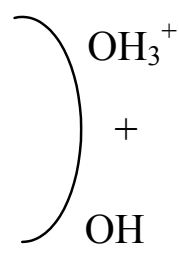

$\mathrm{H}_{2} \mathrm{O}$

$\mathrm{H}_{2} \mathrm{O}$

Figure 4.1 Acid dispersion

In suspension, attractive van der Waals forces attempt to draw the particles together. As the particles approach each other, the diffuse parts of their double layers begin to interact. The similarly charged diffuse layers repel each other. If this electrostatic repulsive force is much greater than the attractive force, the colloid is dispersed. In dispersed colloidal suspensions, particle surfaces do not come into contact, and the particles stay in suspension. When the electrostatic forces are not as strong, the particles can become joined together into a loosely packed structure. This is known as flocculation.

The diffuse layer in electrostatically dispersed slurries can be compressed through the addition of electrolyte salts such as $\mathrm{NaCl}$. This allows the particles to join into a densely packed structure in which they are only separated by a thin hydration layer. This process is called coagulation, and it has been found that the thin hydration layer can act as an effective lubricant for particle rearrangement. This effect has been shown to be 
more prominent at lower $\mathrm{pH}$ values. ${ }^{4.3}$ Coagulation leads to the formation of a particle network which sediments out of the suspension. ${ }^{4.4}$ This would not work well in our deposition technique.

Dispersed slurries tend to work best with our type of colloidal deposition technique. ${ }^{4,4,5}$ Like the repulsive layer in the coagulated slurry, the repulsive electrostatic layer in the dispersed slurry acts as a lubricant for particle flow in the ceramic green body. This allows the particles to rearrange and take on a more tightly packed structure as the vacuum is applied.

We can also produce dispersed suspensions using attached organic molecules. This is called steric dispersion, and it can take various forms. Surfactant molecules can physisorb or chemically bond to the particle surface. ${ }^{4.1}$ These molecules form a brushlike surface and keep individual particles from approaching too closely. The length and character of the surfactant molecules is important. Kramer and Lange found that the length of the attached molecule has an effect on green density. ${ }^{4.6}$ Research on zirconia by Leong showed that polyacrylic acid of MW $2000 \mathrm{~g} / \mathrm{mol}$ reduced the yield stress of the slurry by as much as $80 \%$, while polyacrylic acids of higher molecular weights did not do as well. The highest MW, $750000 \mathrm{~g} / \mathrm{mol}$, actually helped very little due to bridging interactions. ${ }^{4.7}$

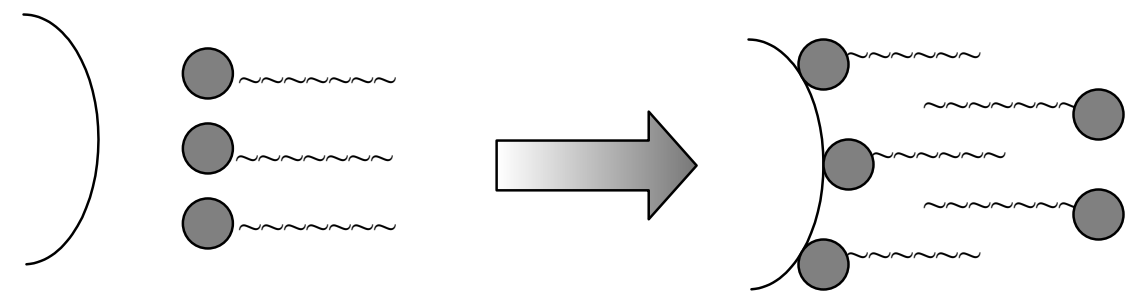

Figure 4.2 Steric dispersion using physisorbed organic molecules 


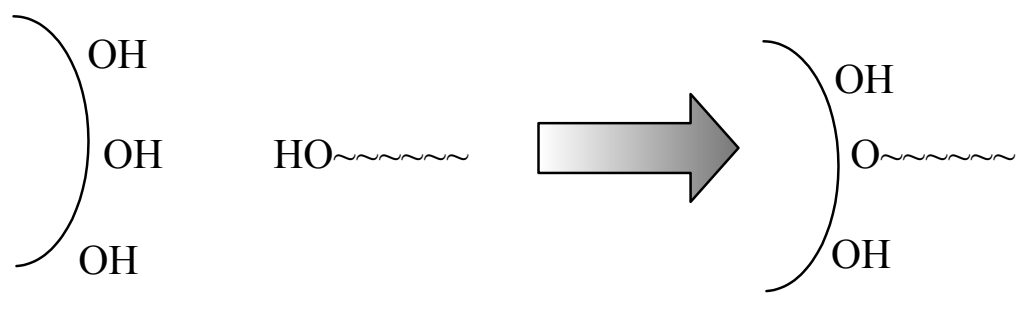

Figure 4.3 Steric dispersion using chemisorbed organic molecules

\subsection{Experimental Results}

We explored the density of films deposited using two different solvents (water and isopropyl alcohol) a surfactant (Brij), $\mathrm{ZrOCl}$ and $\mathrm{YCl}$ salts, and $\mathrm{HCl}$. See the experimental methods (section 2.7) for exact quantities. Relative film densities of the films deposited on rigid substrates were obtained by viewing fracture surfaces of films after sintering (figure 4.4). It was assumed that denser sintered films corresponded to denser films in the green as-deposited state.

Film densities were also obtained by applying films to green LSM / YSZ substrates whose final sintered densities were known (55\%). Observation of film/substrate curvature gave an indication as to whether the film was more or less dense than the substrate. If the film was denser than the substrate, the film would shrink less during sintering, and the film would appear convex. If the film was the same density as the substrate, it would appear flat. If the film was less dense than the substrate, it would appear concave. Pictures of the fracture surfaces of these films were also obtained (figure 4.5). 


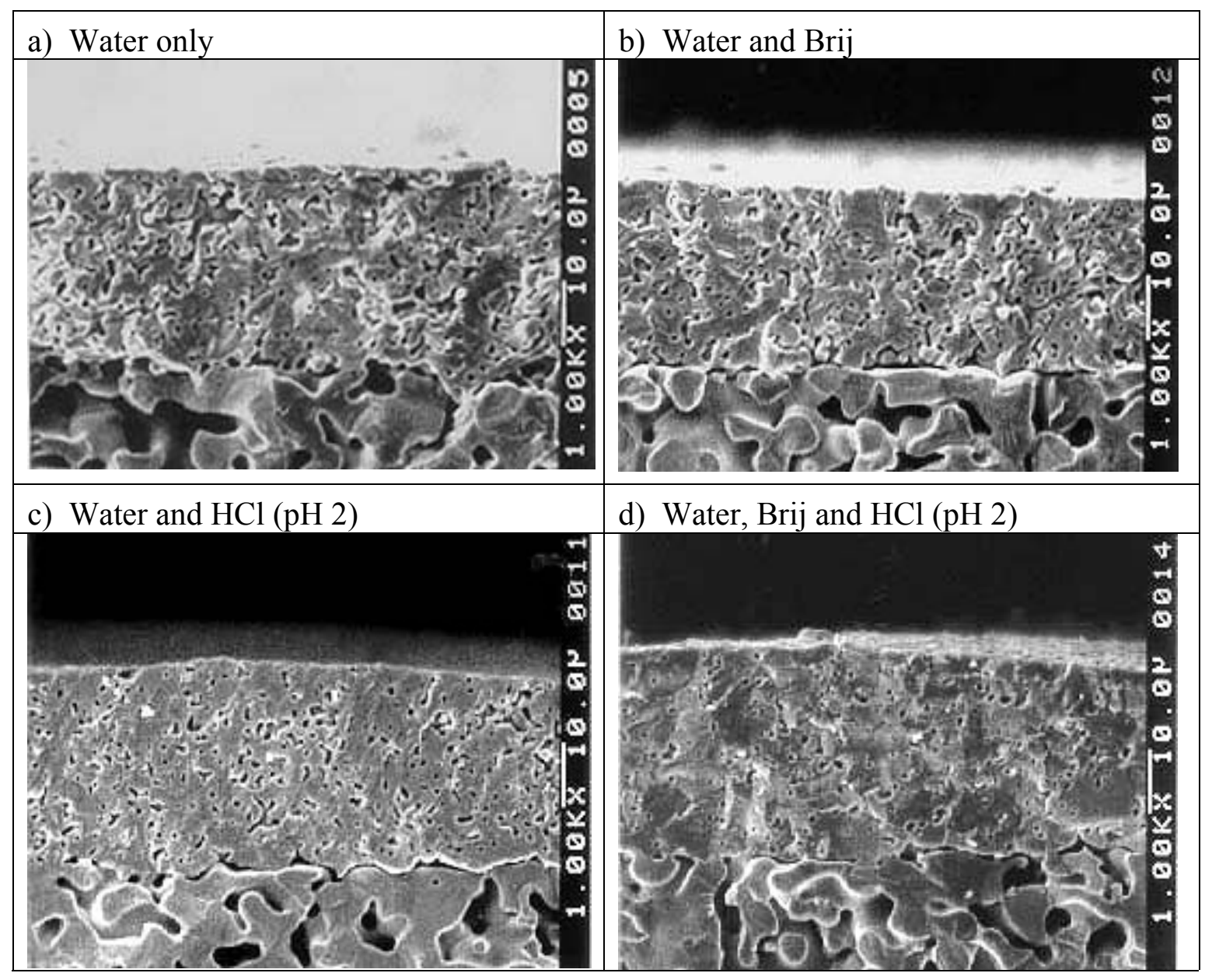

Figure 4.4 Films on Rigid LSM Substrates

\subsubsection{Effect of solvent}

Films deposited using isopropanol were slightly less dense than those deposited using water solutions (not shown).

\subsubsection{Effect of Brij}

The Brij appears to improve the green density slightly in comparison to water only. This is not readily apparent from the picture of the fracture surface on the rigid 
substrate. However, the curvature of the co-fired disk corresponded to a density of roughly $55 \%$ (flat). This was greater than that of the water only film (concave curvature).

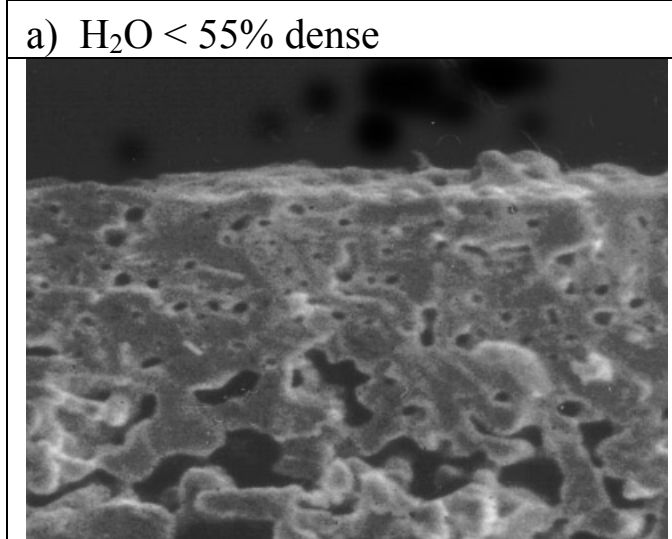

c) Brij $55 \%$ dense

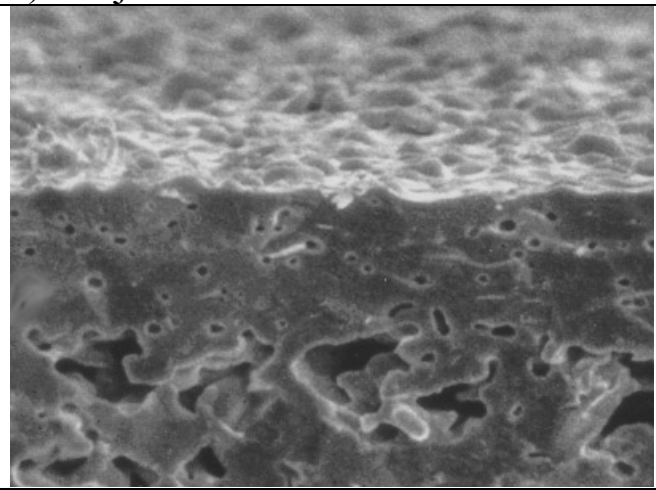

e) Brij + Salts $>55 \%$ dense

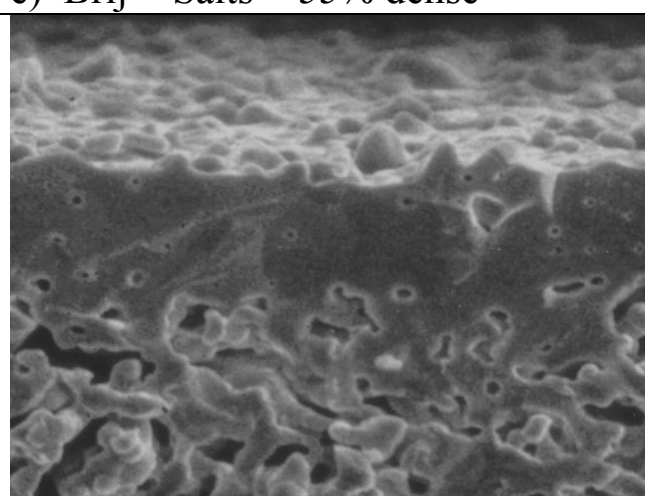

b) IPA $<55 \%$ dense

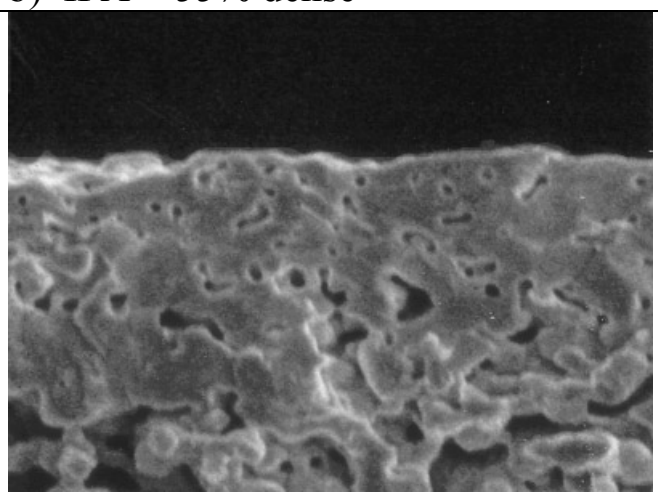

d) Chloride Salts $>55 \%$ dense

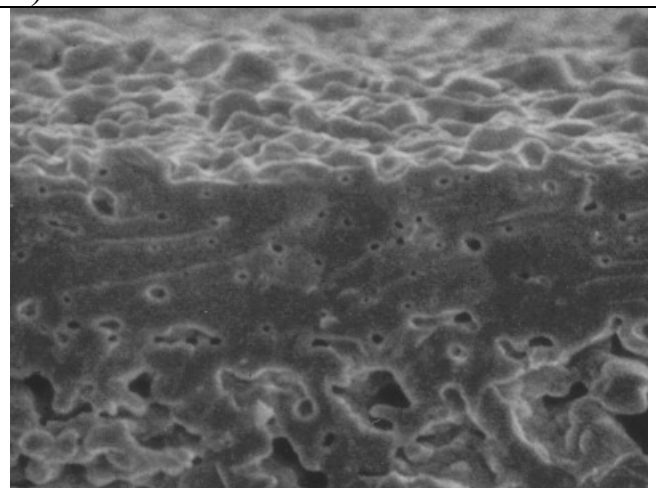

f) $\mathrm{HCl}>55 \%$ dense

Figure 4.5 Films deposited on prefired LSM/YSZ disks $(1000 \mathrm{X})[-10 \mu \mathrm{m}]$ 


\subsubsection{Effect of acid}

The addition of $\mathrm{HCl}$ appears to improve the density of the film substantially. The acid stabilized film on the rigid substrate appears denser than the films deposited using water, IPA and Brij. It is one of the densest films on the co-fired substrates and the convex curvature of the film corresponds with a green density greater than $55 \%$.

\subsubsection{Effect of salts}

The addition of the $\mathrm{ZrOCl}$ and $\mathrm{YCl}$ salts appears to increase the green density of the film on the co-fired substrate in comparison to films deposited using only water, IPA, or Brij (convex curvature). From the pictures of the fracture surfaces, it does not appear significantly denser than the film using acid.

\subsubsection{Effect of salts/acid and Brij together}

Based on the pictures of the fracture surfaces (figure 4.5), the film deposited using the salt and the Brij together appears denser than either the salt or Brij by itself on the cofired substrates. When acid and Brij are used together, they produce the densest film on the rigid substrate and one of the densest films on the co-fired substrates. We attribute most of the increase in density in the films deposited using the salt solutions to the salts' effect on the solution $\mathrm{pH}$. The $\mathrm{pH}$ of the salt solution was about 2.3. This is relatively close to the $\mathrm{pH}$ of the $\mathrm{HCl}$ solutions (2). The only difference between the salt and $\mathrm{HCl}$ solutions is the positively charged ion $\left(\mathrm{ZrO}^{+}, \mathrm{Y}^{+3}\right.$, and $\left.\mathrm{H}^{+}\right)$. The negatively charged counterion is the same $\left(\mathrm{Cl}^{-}\right)$. Since, our particles were observed to stay in suspension, work done on coagulated salt suspensions should not apply here. 


\subsection{Discussion}

Since it is difficult to derive quantitative relationships between processing variables and particle packing, only qualitative arguments will be given here.

It is not surprising that the films should exhibit a higher green density at a $\mathrm{pH}$ of 2 when compared to films deposited at close to neutral $\mathrm{pH}$. As was discussed in section 4.1, for positively charged particles such as zirconia, lower $\mathrm{pH}$ should lead to greater electrostatic charge on the particles. Leong found the highest dynamic mobilities for zirconia at $\mathrm{pH}$ values of 4 and below. ${ }^{4.7}$ A particle's dynamic mobility is proportional to the magnitude of its charge. He also observes that lower $\mathrm{pH}$ values lead to lower solution viscosities in zirconia slurries. ${ }^{4.7}$ Similar effects have also been observed for alumina slurries. ${ }^{4.3}$ As the vacuum is applied, the higher electrostatic charges on the particles should act as a lubricant for particle rearrangement, and this should lead to higher green densities.

Steric dispersion has also been seen to be effective in achieving denser films. It has been observed that zirconia dispersions using polyacrylic acid (PAA) achieve better suspension consolidation in compression as compared to untreated zirconia at the point of zero charge. ${ }^{4.7}$ It is perhaps surprising that the Brij should work better as the $\mathrm{pH}$ is lowered (even better than the acid by itself). There are various explanations for why this might occur.

The extent of the Brij attachment to the particle surface in normal water solutions is not clear. It had been observed that alcohols in water solutions do not bond to ceramic particle surfaces under normal conditions. ${ }^{4.6}$ Research done with polyethylene glycols on platinum showed that polyethylene molecules were only weakly bonded to the particle 
surface. ${ }^{4.8}$ They appear to physisorb to the particle surface. Weakly bonded molecules do not act as effective steric lubricants in the green body because they are pushed out of the way as the green body is compressed. ${ }^{4.6}$ It may be that the low $\mathrm{pH}$ catalyzes the bonding of the $\mathrm{OH}$ group on the Brij molecules to the particle surface. This may be similar to the acid catalyzed dehydration reaction to form esters from alcohols. ${ }^{4.9}$ More tightly bonded Brij molecules should act as a more effective steric lubricant, which should lead to denser green bodies.

It is also observed that higher surfactant concentrations in solution can lead to lower solution viscosities. ${ }^{4.7}$ It may be that some Brij bonds to the particle surfaces at all $\mathrm{pH}$ values. But if the lower $\mathrm{pH}$ increases the number of Brij molecules attached to the particle surfaces, this still may help. It has also been observed that greater amounts of polyethylene glycol (MW 2000) absorb on montmorillonite clays at $\mathrm{pH}$ values lower than 4. However, these results may not be directly applicable to our results since the clay is negatively charged in solution and researchers attribute the increased PEG absorption to agglomeration of the clay particles near the IEP. ${ }^{4.10}$

The increased dispersive ability of the Brij may also have something to do with the behavior of the polyethylene and hydrocarbon chains in solution. The acid could interact with the oxygen atoms in the polyethylene oxide section of the Brij chain. The chain exists in a coiled state in the solution and interaction with acid could act to stretch out the chain due to repulsion between oxygen atoms. ${ }^{4.8}$ Perhaps the chains themselves become charged and extend the range of electrostatic repulsion, as has been seen in some other systems. ${ }^{4.2,4.5}$ It is also possible that the opposite reaction takes place and the acid makes the polyethylene chains more attractive to the particle surface. Research done on 
metals shows that polyethylene glycol molecules (very similar structure to Brij minus the hydrocarbon chain) are attracted to metal surfaces through the oxygen groups in the polyethylene oxide chain. ${ }^{4.11}$ However, metal surfaces are generally negatively charged in aqueous solutions, as opposed to oxide surfaces, which are positively charged. ${ }^{4.12}$

It is evident that more research should be done to explore the relationship between the enhanced packing density and Brij/acid interaction. Perhaps infrared techniques might be useful here.

\section{References}

[4.1] Lange, F. F. Colloidal processing of powder for reliable ceramics. Current Opinion in Solid State and Materials Science 1998, 3:496-500.

[4.2] Rahaman, M. N., Ceramic Processing and Sintering, Marcel Dekker, Inc. NY. 1995.

[4.3] Chang, J. C., Lange, F. F., and Pearson, D. S., Viscosity and Yield Stress of Alumina Slurries Containing Large Concentrations of Electrolyte. J. Am. Ceram. Soc., 77 [1] 19-24 (1994).

[4.4] Velamakanni, B. V., Chang, J.C., Lange, F. F., and Pearson, D. S. New Method for Efficient Colloidal Particle Packing via Modulation of Repulsive Lubricating Hydration Forces. Langmuir, 6 [7] 1323-1325 (1990).

[4.5] Lange, F. F. Powder Processing Science and Technology for Increased Reliability. J. Am. Ceram. Soc., 72 [1] 3-15 (1989).

[4.6] Kramer, T. and Lange, F. F., Rheology and Particle Packing of Chem- and PhysAdsorbed, Alkylated Silicon Nitride Powders. J. Am. Ceram. Soc., 77 [4] 922-28 (1994).

[4.7] Leong, Y. K., Exploitation of interparticle forces in the processing of colloidal ceramic materials. Materials \& Design, 15 [3] 141-7 (1994).

[4.8] Brugger, P-A, Cuendet, P., and Gratzel, M. Hydrogen Evolution from Water under Visible Light Illumination. J. Am. Chem. Soc., 103 [11] 2923-7 (1981).

[4.9] McMurry, J., Organic Chemistry, $3^{\text {rd }}$ Edition. Brooks/Cole Publishing Company, Pacific Grove. 1992. 
[4.10] Zhao, X., Urano, K., and Ogasawara, S. Adsorption of polyethylene glycol from aqueous solution on montmorillonite clays. Colliod Polym. Sci., 267 [10] 899-906 (1989).

[4.11] Lee, P. C. and Meisel, D. Surface-Enhanced Raman Scattering of ColloidStabilizer Systems. Chemical Physic Letters, 99 [3] 262-5 (1983).

[4.12] Kiwi, J., Kalyanasundaram, K., and Gratzel, M. Visible Light Induced Cleavage of Water into Hydrogen and Oxygen in Colloidal and Microheterogeneous Systems. Structure and Bonding, 49 (1982). 


\section{Density and Film Thickness}

\subsection{Thinner Films Are Denser}

Particle packing is not the only factor that affects film density. We have observed that films deposited on LSM substrates exhibit a thickness/density effect. Thinner films appear to densify more than thicker films. It is not immediately obvious why a thick film should densify less than a thin film. The earlier discussion of constrained sintering suggested why constrained sintering might lead to more porous structures. Because the constraints lie in the plane of the film, there is no fundamental reason why constrained sintering alone should lead to density variations with film thickness.

\subsection{Experimental Results}

Films were deposited in the usual manner on LSM tubes and plates. The films were deposited using the $0.70 \mu \mathrm{m}$ YSZ powder from water solution with $\mathrm{HCl}$ at a $\mathrm{pH}$ of 2 with no other additives. The films were deposited on tubes and plates of LSM and plates of YSZ. For films sintered on LSM substrates, the film density became progressively worse as the films became thicker (figure 5.1). The films deposited on YSZ substrates, on the other hand, sintered the same regardless of thickness (not shown). We also observed that films of similar thickness sintered more readily on LSM substrates than on YSZ substrates (figure 5.2). A set of experiments was done doping YSZ films sintered 
on rigid YSZ substrates with fixed amounts of $\mathrm{MnO}$. The results of these experiments are shown in figure 5.3.
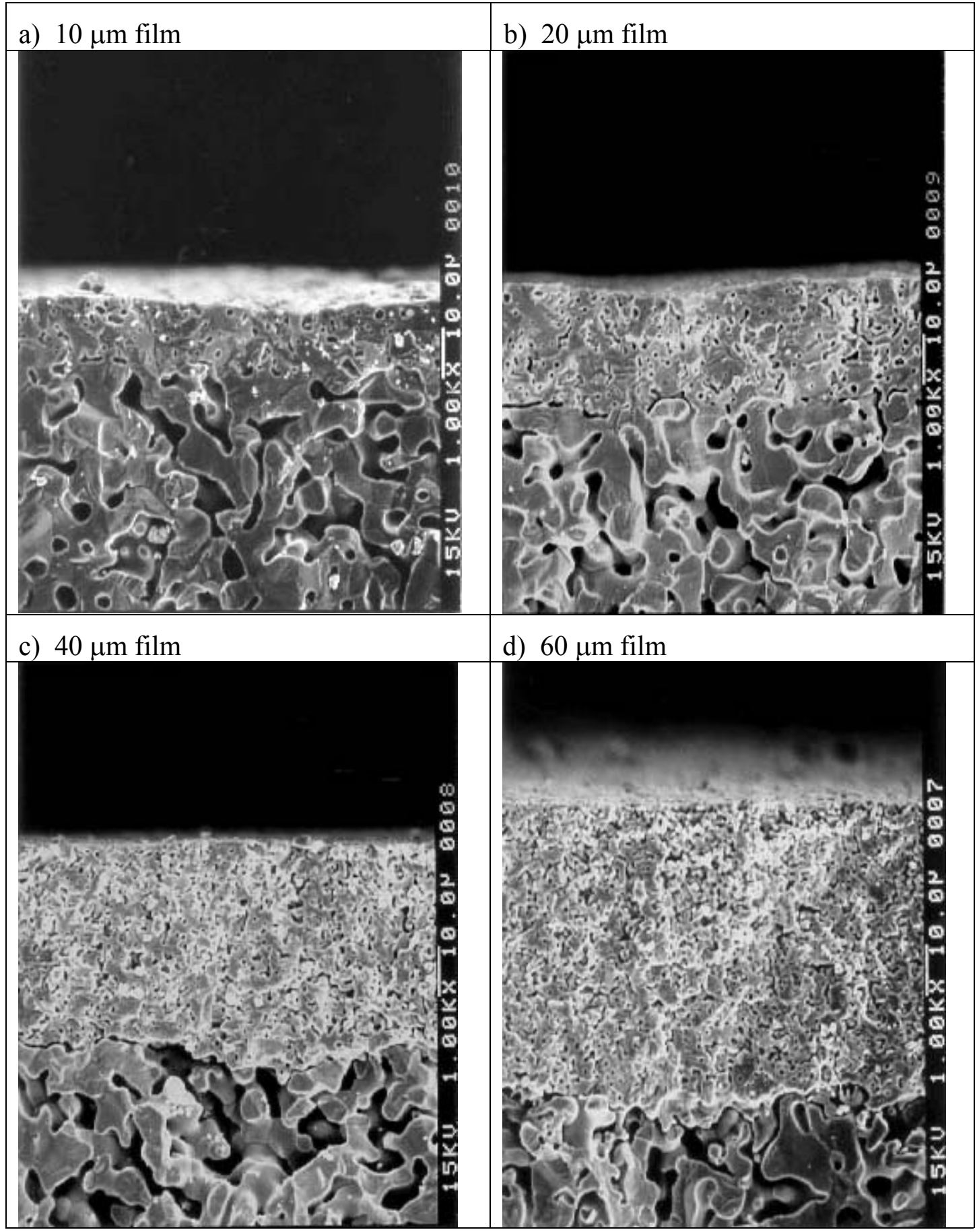

Figure 5.1 Films deposited using $\mathrm{HCl}$, water, and $0.70 \mu \mathrm{m}$ powder 


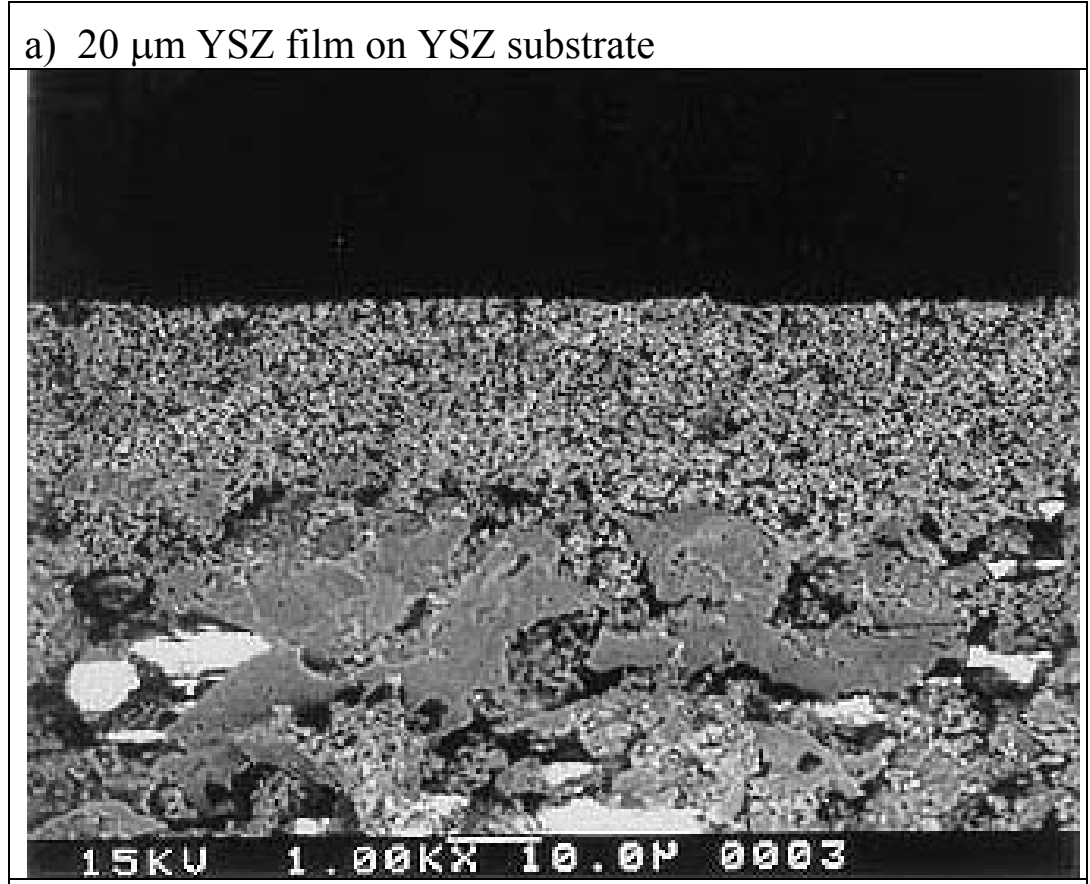

b) $30 \mu \mathrm{m}$ YSZ film on LSM substrate

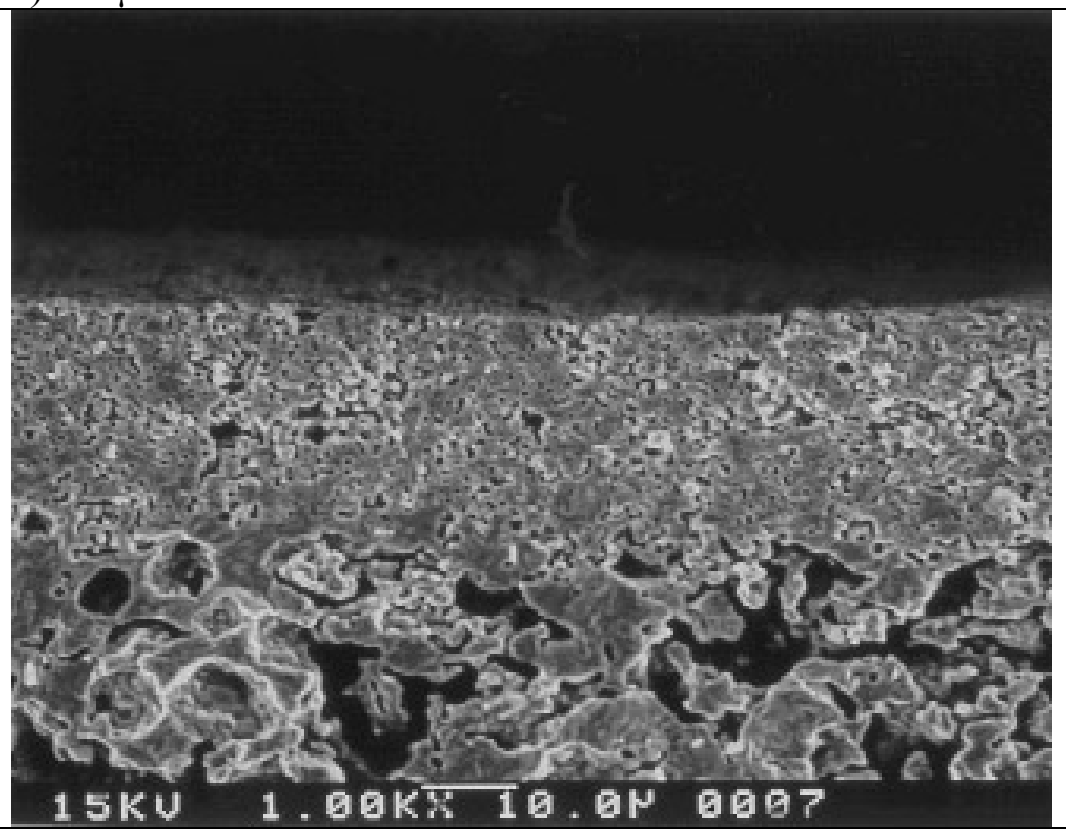

Figure 5.2 Effect of substrate material on constrained YSZ films fired at $1400^{\circ} \mathrm{C}$ 


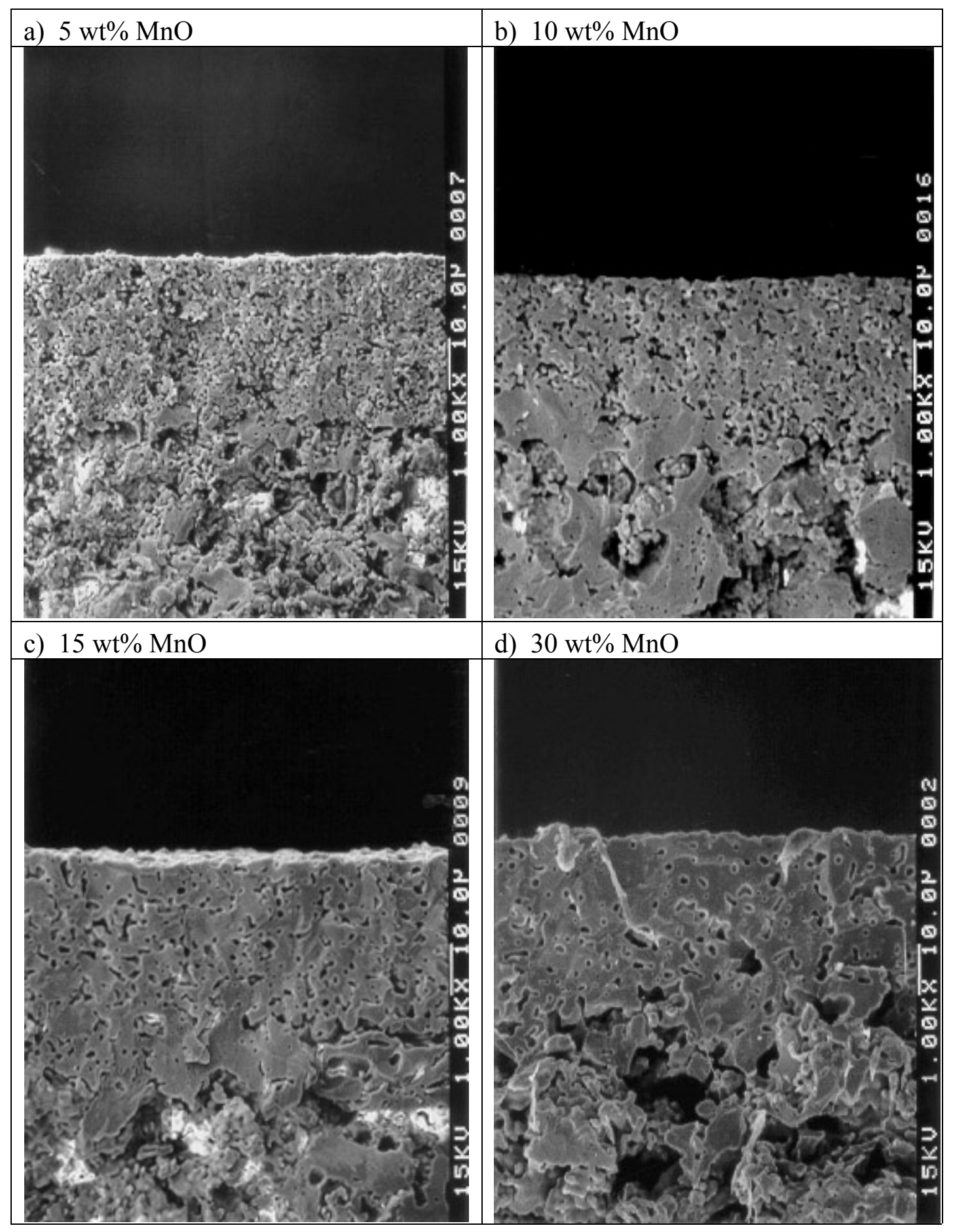

Figure 5.3 Effect of $\mathrm{MnO}$ doping on sintering of YSZ 


\subsection{Discussion}

It appears that some element in the LSM substrates is acting as a sintering aid in the YSZ films. Over the years a wide variety of sintering aids have been added to zirconia films to enhance sintering. Additions of $\mathrm{Al}_{2} \mathrm{O}_{3}, \mathrm{NiO}, \mathrm{TiO}_{2}, \mathrm{Bi}_{2} \mathrm{O}_{3}, \mathrm{Fe}_{2} \mathrm{O}_{3}$, and $\mathrm{MgO}$ have all been used as sintering aids. ${ }^{5.1,5.2,5.3}$ Some additives work better than others, depending on which zirconia phase is desired and what structural and electronic properties are desired. For instance, glasses have been used to enhance sintering in calcia-stabilized zirconia but their use leads to ionically insulating phases at grain boundaries. $^{5.4}$

Since we have not purposefully introduced a sintering additive into our films, it must be coming from the substrate. This has been observed for zirconia films sintered on alumina substrates contaminated with impurities. ${ }^{5.5}$ Of the substrate constituents, Mn seems the best candidate for a sintering additive. In fuel cell structures, $\mathrm{Mn}$ is seen to diffuse into YSZ films from the LSM electrode at temperatures ranging from 1200$1500^{\circ} \mathrm{C}$. As mentioned previously, Mn depletion at the electrode/electrolyte interface can lead to the formation of insulating La and Sr phases. Excess Mn is generally introduced to alleviate this effect. The maximum solubilty of Mn into $8 \mathrm{~mol} \% \mathrm{YSZ}$ (ours) is roughly $15 \mathrm{~mol} \%$ at $1500^{\circ} \mathrm{C}$ in air. ${ }^{5.6}$

It also appears that the thinner films exhibit a higher concentration of the substance. This would be consistent with some chemical rapidly diffusing from the substrate throughout the film. It has been experimentally determined that, in polycrystalline samples, Mn diffuses primarily via the grain boundary. ${ }^{5.7}$ Based on experiments done using $\mathrm{Mn}_{2} \mathrm{O}_{3}$ on YSZ, the diffusion coefficient would be $5 \times 10^{-11} \mathrm{~cm}^{2} / \mathrm{s}$ 
at $1400^{\circ} \mathrm{C} .{ }^{5.7}$ This has been confirmed by others using similar materials. ${ }^{5.8}$

Experimentally measured concentration profiles show that concentration is at roughly $10 \% \mathrm{Mn}$ up to the first $40 \mu \mathrm{m}$ or so when annealed at $1500^{\circ} \mathrm{C}$ for 10 hours. ${ }^{5.6} \mathrm{Mn}$ diffusion throughout a $30 \mu \mathrm{m}$ film would be very likely at $1400^{\circ} \mathrm{C}$.

How the Mn enhances sintering is not clear. In calcia-stabilized zirconia, $\mathrm{MgO}$ has successfully been used as a sintering aid. $\mathrm{MgO}$ may aid sintering by reducing the surface diffusion coefficient and thereby suppressing the coarsening rate, similar to what it does in alumina. This mechanism should also inhibit grain growth. ${ }^{5.9} \mathrm{CuO}$ can also enhance sintering in tetragonal yttria-stabilized zirconia ( $3 \mathrm{~mol} \%)$ by introducing a eutectic phase which allows liquid phase sintering and enhances diffusion. $\mathrm{Cu}$ additions are seen to enhance grain growth. ${ }^{5.10}$ In ceria stabilized zirconia, both $\mathrm{Mn}$ and $\mathrm{Cu}$ were found to increase sintering rates but not reduce temperatures. TEM studies confirmed the presence of a $\mathrm{Cu}$ containing liquid phase boundary while none could be found for $\mathrm{Mn}$. $\mathrm{Cu}$ appears to work better than $\mathrm{Mn}$. Both $\mathrm{CuO}$ and $\mathrm{MnO}$ were found to inhibit grain growth in this case, and $\mathrm{MnO}_{2}$ was found to inhibit grain growth more.

Studies have also been done using molten $\mathrm{Mn}$ and porous zirconia films. In one study, molten Mn was infiltrated into a plasma sprayed YSZ ( $8 \mathrm{~mol} \%$ ). In this study manganese is seen to enhance grain growth. The authors think that easy diffusion of manganese and mass transport leads to enhanced coalescence and growth of particles. ${ }^{5.11}$ Liquid manganese has also been infiltrated into plasma sprayed monoclinic zirconia. The zirconia was observed to change to the cubic phase when heated. The authors of this study see evidence of liquid phase sintering and grain growth at $1573 \mathrm{~K} .{ }^{5.12}$ The phase diagram does not appear to support this. ${ }^{5.13}$ 
What are the consequences for the ionic conductivity of the electrolyte film? Mn appears to increase the ionic conductivity of YSZ slightly at concentrations of $4 \mathrm{~mol} \%$ at oxygen partial pressures of $10^{3} \mathrm{~Pa}$ or higher. Lower oxygen partial pressures of $10^{-10} \mathrm{~Pa}$ can drop the conductivity almost an order of magnitude. This is attributed to the change of Mn valence state when it goes from high to low oxygen partial pressure ( +3 to +2$){ }^{5.14}$ The transference number of the ionic conductor appears to stay near unity however. ${ }^{5.6}$ The oxidation state of the $\mathrm{Mn}$ in solution can also be changed by annealing in hydrogen. ${ }^{5.15}$

\section{References}

[5.1] Chen, S., Deng, W., and Shen, P., Stability of cubic $\mathrm{ZrO} 2$ (10 mol\% Y2O3) when alloyed with $\mathrm{NiO}, \mathrm{Al}_{2} \mathrm{O}_{3}$, or $\mathrm{TiO}_{2}$ : implications to solid electrolytes and cermets. Mat. Sci. \& Eng. B., 22, 247-255 (1994).

[5.2] Boutz, M. M. R., Winnubst, A. J. A., Hartgers, F., and Burgraaf, A. J., Effect of additives on densification and deformation of tetragonal zirconia. J Mat Sci Let., 29, 5374-5382 (1994).

[5.3] Michalowsky, L., and Schabel, H-D., Sintering of Coprecipitated MgO-partially Stabilized Zirconia. Ceram. Intl. 16, 33-37 (1990).

[5.4] Chiou, B., Hsu, W., and Duh, J., Fabrication and Electrical Behavior of Liquid Phase Sintered Zirconia. Ceram. Intl. 14, 7-16 (1988).

[5.5] Ioannou, A. S., and Maskell, W. C., Influence of substrate composition on the sintering behavior of zirconia thick films. J. Mat. Sci. Let., 11, 1623-1625 (1992).

[5.6] Kawada, T., Sakai, N., Yokokawa, H., Dokiya, M., and Anzai, I., Reaction between solid oxide fuel cell materials. Solid State Ionics, 50, 189-196 (1992).

[5.7] Waller, D., Sirman, J. D., and Kilner, J. A., Manganese Diffusion in Single Crystal and Polycrystalline Yttria Stabilized Zirconia. Proceedings of the Fifth International Symposium on Solid Oxide Fuel Cells (SOFC-V). Stimming, U., Singhal, S.C., Tagawa, H., and Lehnert, W., eds. Electrochemical Society (pub). Proceedings Volume 97-40. pp.1140-1149 (1997). 
[5.8] Maschio, S., Sbaizero O., Meriani, S., and Bischoff, E., Sintering aids for ceriazirconia alloys. J. Mat. Sci., 27, 2734-2738 (1992).

[5.9] Wu, S., and Brook, R. J., Sintering Additives for Zirconia Ceramics. Trans. J. Br. Ceram. Soc., 82, 200-205 (1983).

[5.10] Shi, J. L., Yen, T. S., and Schubert, H., Effect of small amounts of additives on the sintering of high-purity Y-TZP. J. Mat. Sci., 32, 1341-1346 (1997).

[5.11] Shinozaki, N., Sonoda, M., and Mukai, K. Wettability, Surface Tension, and Reactivity of the Molten Manganese/Zirconia-Yttria Ceramic System. Met. \& Mat. Trans. A., 29A, 1121-25 (1998).

[5.12] Ohmori, A., Zhou, Z., and Murakami, K., Transformation of plasma-sprayed zirconia coating from monoclinic to cubic structure by liquid phase sintering. J. Mat. Sci. Let. 14, 38-40 (1995).

[5.13] Phase Diagrams for Ceramists, Smith, G, ed. American Ceramic Society. 1981. Pg.104.

[5.14] Kawada, T., Sakai, N., Yokokawa, H., and Dokiya, M., Electrical Properties of transition-metal-doped YSZ. Solid State Ionics, 53-56, 418-425 (1992).

[5.15] Appel, C. C., Botton, G. A., Horsewell, A., and Stobbs, W. M., Chemical and Structural Changes in Manganese-Doped Yttria-Stabilized Zirconia Studied by Electron Energy Loss Spectroscopy Combined with Electron Diffraction. J. Am. Ceram. Soc., 82 [2] 429-35 (1999). 


\section{Electrochemical Testing}

\subsection{Co-fired cells}

The films produced on rigid substrates are not dense enough in inhibit electrical shorts when electrodes are applied. This makes it impossible to test these cells as fuel cells or do substantive electrochemical testing on them. We have been able to produce dense co-fired films, however; and it is possible to conduct electrochemical tests on these. Many of the materials interaction issues should be identical in both types of cells, and it is very likely that data obtained from the co-fired films will be directly transferable to the constrained films once the deposition technology is optimized. Testing on these cells also provides proof that a fuel cell can be constructed using a cathode-supported structure via colloidal techniques.

There is a variety of ways to test the electrical properties of a fuel cell. We typically employ current/voltage techniques and impedance spectroscopy. These techniques are common in the field. We fire our films at $1400^{\circ} \mathrm{C}$, and we have to be alert to the formation of reaction layers between the film and substrate. These reaction layers are generally too thin to be detected by conventional means. Electrochemical tests are often the only way of detecting these reaction layers short of transmission electron microscopy (TEM). Electrochemical testing can also provide information on the geometry of the film/substrate interface and the substrate microstructure. 


\subsection{Current/Voltage Characterization Techniques}

We can learn a lot about the electrochemical properties of a system by varying the potential and measuring the current or vice versa. Two techniques that we employ are current interrupt and IV (current/voltage) curves. Current interrupt techniques can provide valuable data on the resistances present in the cell and can act as a complement to data obtained by impedance spectroscopy and other methods. The current interrupt method is very simple and consists of applying a constant current to the cell, allowing the cell to equilibrate and then abruptly terminating the current. The cell potential is monitored during this process as a function of time. Typical results are shown in figure 6.1. The vertical portion of the voltage curve can be directly correlated with the ohmic resistance of the cell. In solid oxide fuel cell systems this resistance is approximately that of the electrolyte film as it has by far the greatest ohmic resistance. The part of the curve that slowly approaches the equilibrium voltage at the new potential is typically attributed to time dependent polarizations, which occur on the electrode surfaces. This method is similar to chronopotentiometric techniques commonly employed in electrochemical systems. ${ }^{6.1}$ 


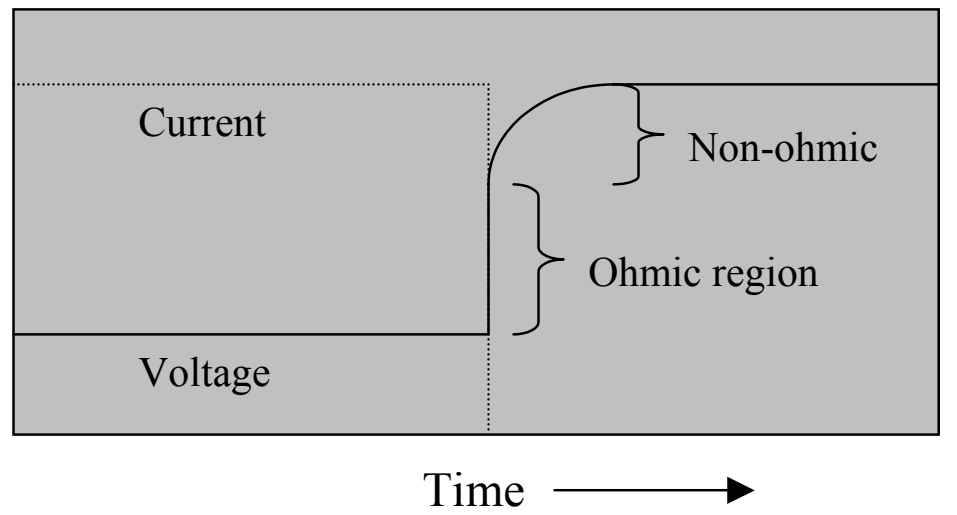

Figure 6.1 Current Interrupt

A complementary characterization method involves current/voltage (IV) curves. This is the most common way in which fuel cells are characterized. IV curves provide information on the voltage drop in the cell as current is applied and allow us to obtain the maximum power density of the cell. A typical IV curve appears in figure 6.2. The curve is generated by slowly increasing the current run through the fuel cell. As the current increases, the voltage falls from its open circuit potential (no load) to a voltage where the cell essentially shuts down. The curve is generally split into three parts. The first part corresponds to a region dominated by the activation energy of the electrode reactions. The ohmic resistance of the cell dominates the second region of the plot, and the third region is dominated by gas diffusion. ${ }^{6.2}$ Taking the data from the plot and multiplying the voltage and the current gives us a power curve. This curve is useful because it tells us at which current we can achieve a particular power density, and the maximum power density provides a benchmark for the quality of the cell. 


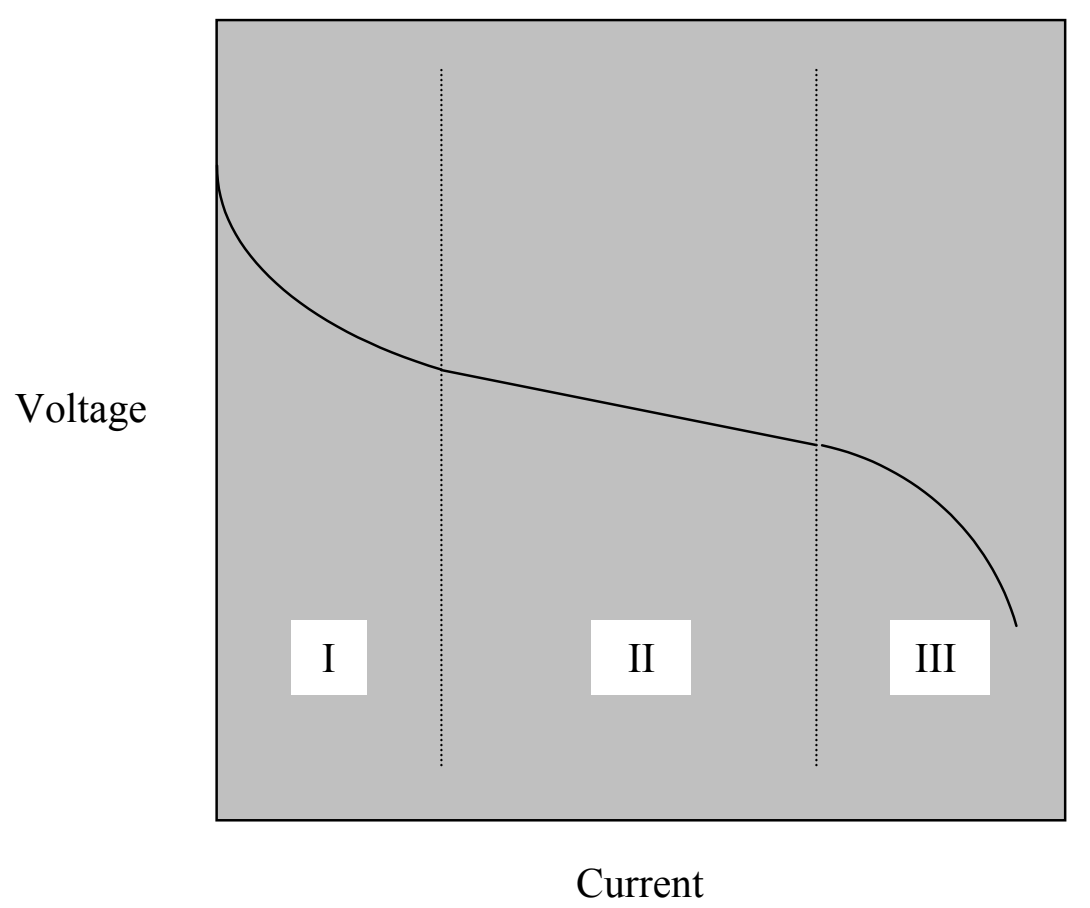

Figure 6.2 Typical IV curve

\subsection{Impedance Spectroscopy}

Impedance spectroscopy is based on the concept of impedance, the effective resistance to an oscillating current due to ohmic, inductive, and capacitive effects. A sinusoidal voltage or current of small magnitude is applied to a cell, and the corresponding current or voltage is measured. The impedance from the cell is compared with equivalent circuits made up of resistors and capacitors that generate similar impedance response. Knowledge of the different electrochemical processes occurring in the cell allows researchers to assign each circuit element a corresponding electrochemical process. 
The equivalent circuit for a simple electrode process might look something like that in figure 6.3 where $R_{\Omega}$ is the resistance of the electrolyte, $R_{c t}$ is the charge transfer resistance, $\omega$ is the frequency of the perturbation, $C_{d}$ is the capacitance of the double layer, and $Z_{\mathrm{w}}$ is the Warburg impedance. The Warburg impedance is taken to represent a resistance to mass transfer.

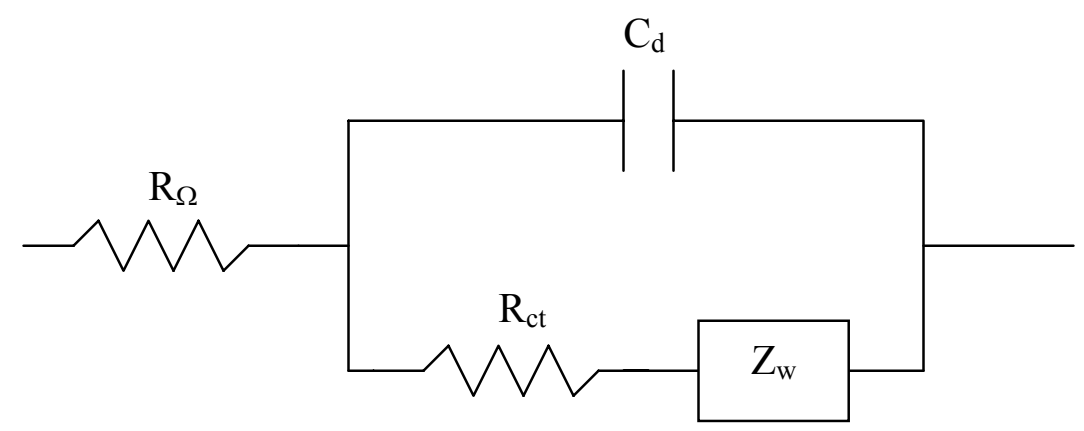

Figure 6.3 Equivalent circuit for simple electrode

The impedance $(Z)$ can be expressed as the summation of a real and imaginary part, $Z=Z_{R e}+i Z_{I m}$. It can be shown that the real and imaginary parts of the impedance can be described by the following equations $6.1,6.3$

$$
\begin{gathered}
Z_{\mathrm{Re}}=R_{\Omega}+\frac{R_{c t}+\sigma \omega^{-\frac{1}{2}}}{\left(\sigma \omega^{\frac{1}{2}} C_{d}+1\right)^{2}+\omega^{2} C_{d}^{2}\left(R_{c t}+\sigma \omega^{-\frac{1}{2}}\right)^{2}} \\
Z_{\mathrm{Im}}=\frac{\omega C_{d}\left(R_{c t}+\sigma \omega^{-\frac{1}{2}}\right)^{2}+\sigma^{2} C_{d}+\sigma \omega^{-\frac{1}{2}}}{\left(\sigma \omega^{\frac{1}{2}} C_{d}+1\right)^{2}+\omega^{2} C_{d}^{2}\left(R_{c t}+\sigma \omega^{-\frac{1}{2}}\right)^{2}}
\end{gathered}
$$


where $\sigma$ is a constant which depends on the diffusion coefficients and concentrations of the species reacting at the electrode. In general, the impedance of the cell is constant at constant frequency but changes as the frequency of the signal is varied from high to low.

Figure 6.4 shows a typical impedance plot (variously referred to as a Sluyters, Nyquist, or Cole-Cole plot) for an electrode. In this plot, the frequency of the signal decreases from left to right. We can see where the shape of the curve comes from by considering the limiting forms of the equations for the real and imaginary parts of the impedance. At low frequencies, the real and imaginary parts of the impedance should be linearly related.

$$
Z_{\mathrm{Im}}=Z_{\mathrm{Re}}-R_{\Omega}-R_{c t}+2 \sigma^{2} C_{d}
$$

At high frequencies, the real and imaginary parts of the impedance should form a semicircle of radius $R_{\mathrm{ct}} / 2$.

$$
\left(Z_{\mathrm{Re}}-R_{\Omega}-\frac{R_{c t}}{2}\right)^{2}+Z_{\mathrm{Im}}^{2}=\left(\frac{R_{c t}}{2}\right)^{2}
$$

The impedance spectra for solid oxide fuel cells are slightly different than those for simple electrodes (figure 6.5). The impedance plot exhibits an intercept at low frequency that is not always encountered in aqueous electrodes. This intercept is attributed to a diffusional impedance $\left(Z_{D}\right)$ which becomes more dominant at lower frequencies. ${ }^{6.4}$ 


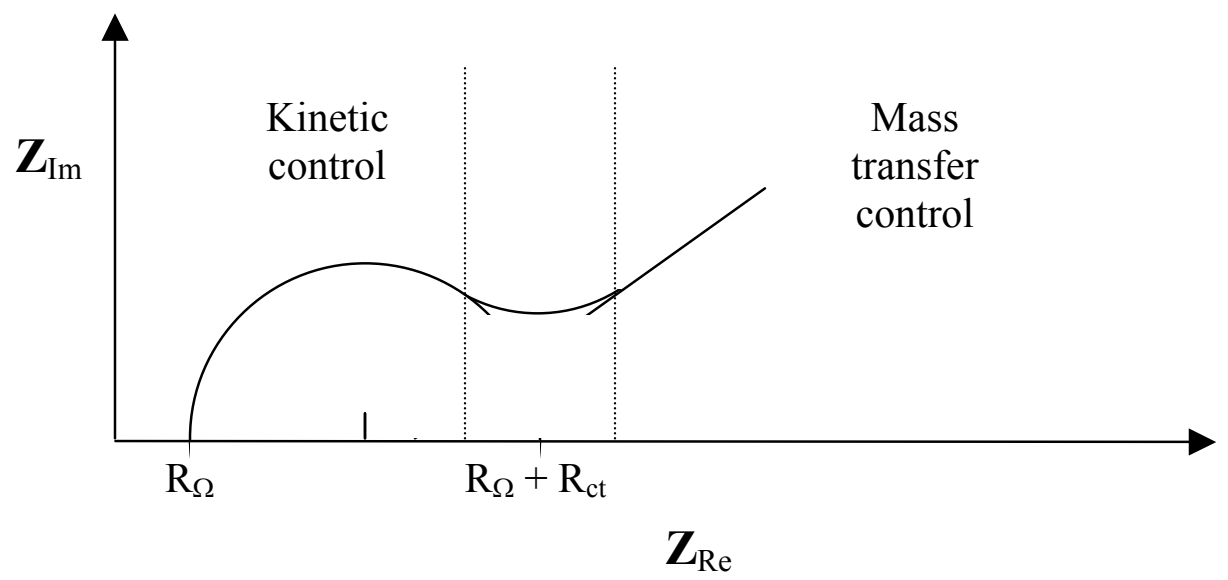

Figure 6.4 Impedance plot for simple electrode process

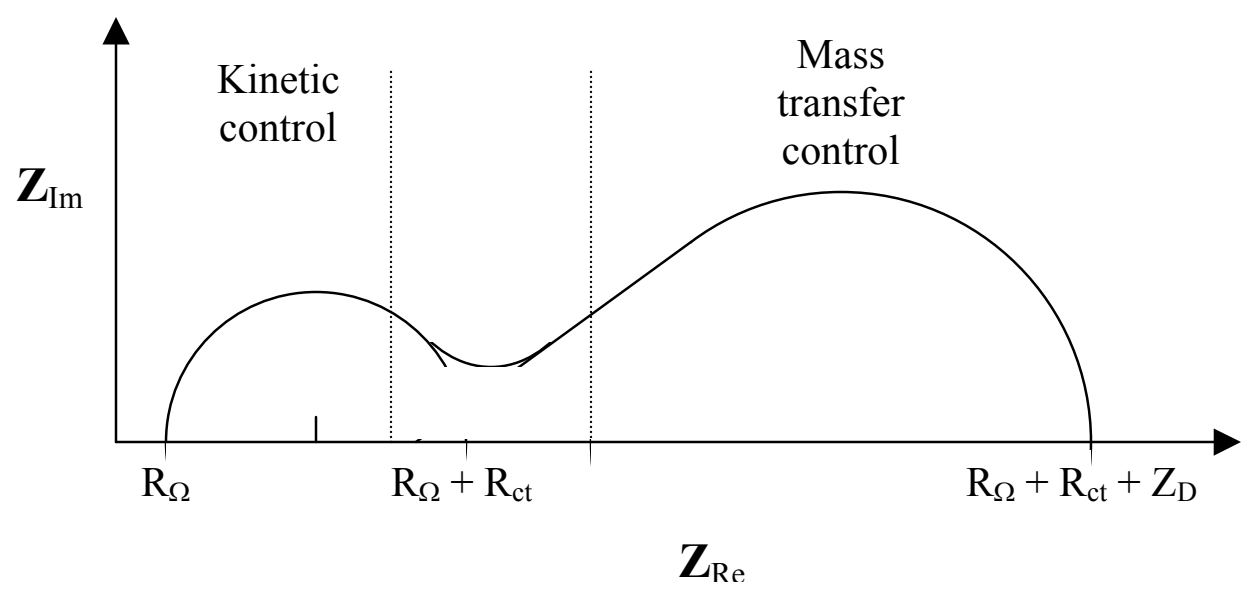

Figure 6.5 Typical SOFC impedance plot

\subsection{Experimental Results}

IV and current interrupt tests were done using an EG\&G Princeton Applied Research Model 371 Potentiostat-Galvanostat interfaced with a PC running LABVIEW. 
Impedance was done using a Solartron Instruments SI 1260 Impedance/Gain Phase Analyzer. A sinusoidal voltage of $20 \mathrm{mV}$ was applied to the cell at frequency range of $100 \mathrm{kHz}$ to $0.1 \mathrm{~Hz}$. The data presented in this section comes from yttria stabilized zirconia (YSZ) film fabricated on a co-fired lanthanum strontium manganate (LSM) substrate. The film was deposited from an isopropanol suspension using the as received TOSOH YSZ. See experimental methods (section 2.7) for details on substrate preparation. While this method of producing cells is different from the constrained method, the film deposition is done via vacuum infiltration, and it is our hope that the impedance data from the films deposited on rigid substrates will be similar.
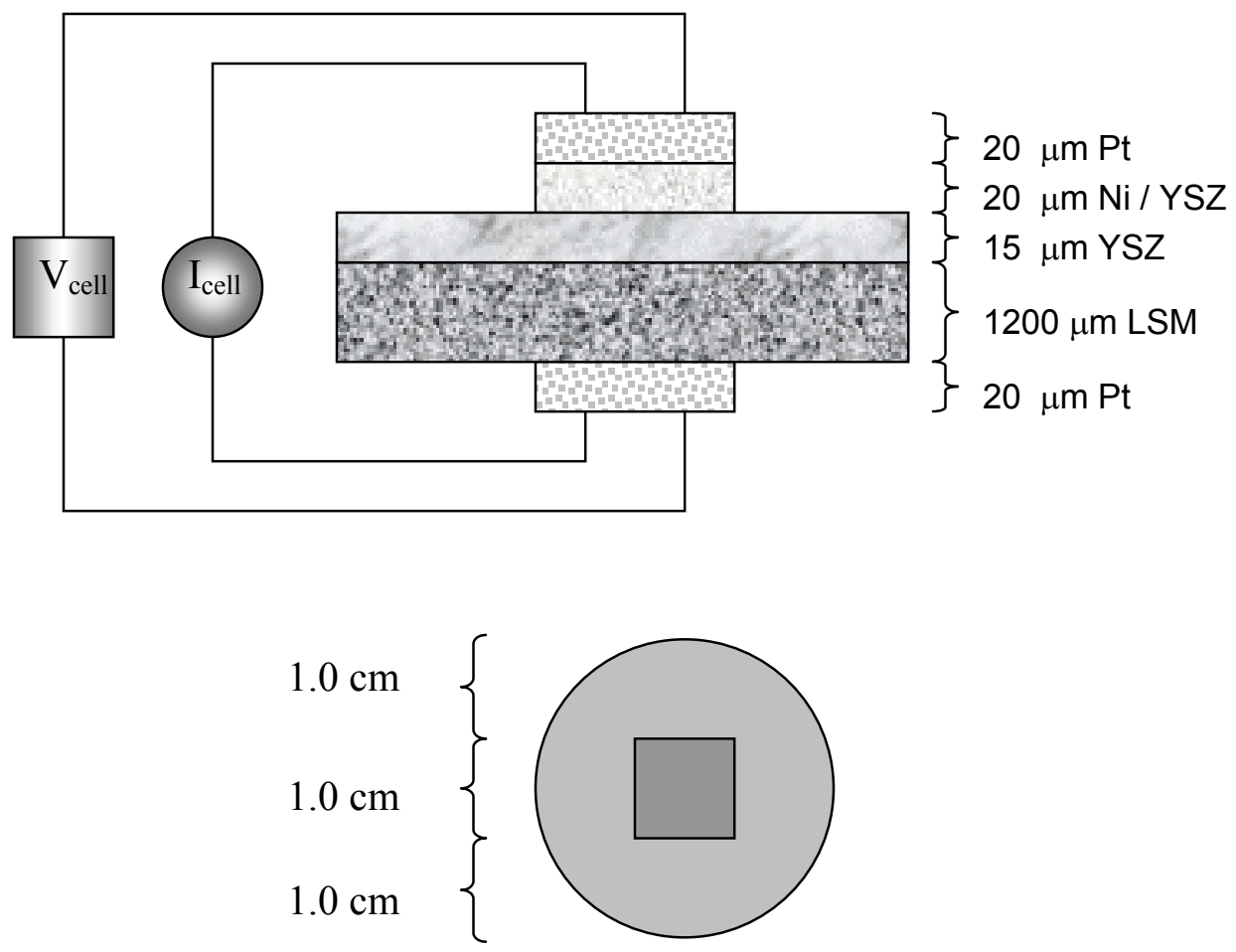

Figure 6.6 Testing configuration 
We test our cells using the electrode configuration shown in figure 6.6. The LSM substrate is the cathode. The $15 \mu \mathrm{m} \mathrm{YSZ} \mathrm{film} \mathrm{is} \mathrm{the} \mathrm{electrolyte.} \mathrm{A} \mathrm{mixture} \mathrm{of} \mathrm{nickel}$ oxide $(\mathrm{NiO})$ and $\mathrm{YSZ}$ is used for the anode. The $\mathrm{NiO}$ reduces to nickel $(\mathrm{Ni})$ when the anode is exposed to hydrogen. Platinum paste and platinum screen are used as the current collectors. A $1 \mathrm{~cm}^{2}$ area of the cell is tested. We do not use a reference electrode in our cell. Problems with the reference electrode are discussed in section 6.5. The IV curve for a co-fired cell run on moist hydrogen $\left(3 \%\right.$ water) and air at $800^{\circ} \mathrm{C}$ appears in figure 6.7. The impedance data for the same cell taken in air after running current also appears in figure 6.8 .

LSM / YSZ Fuel Cell IV Curve

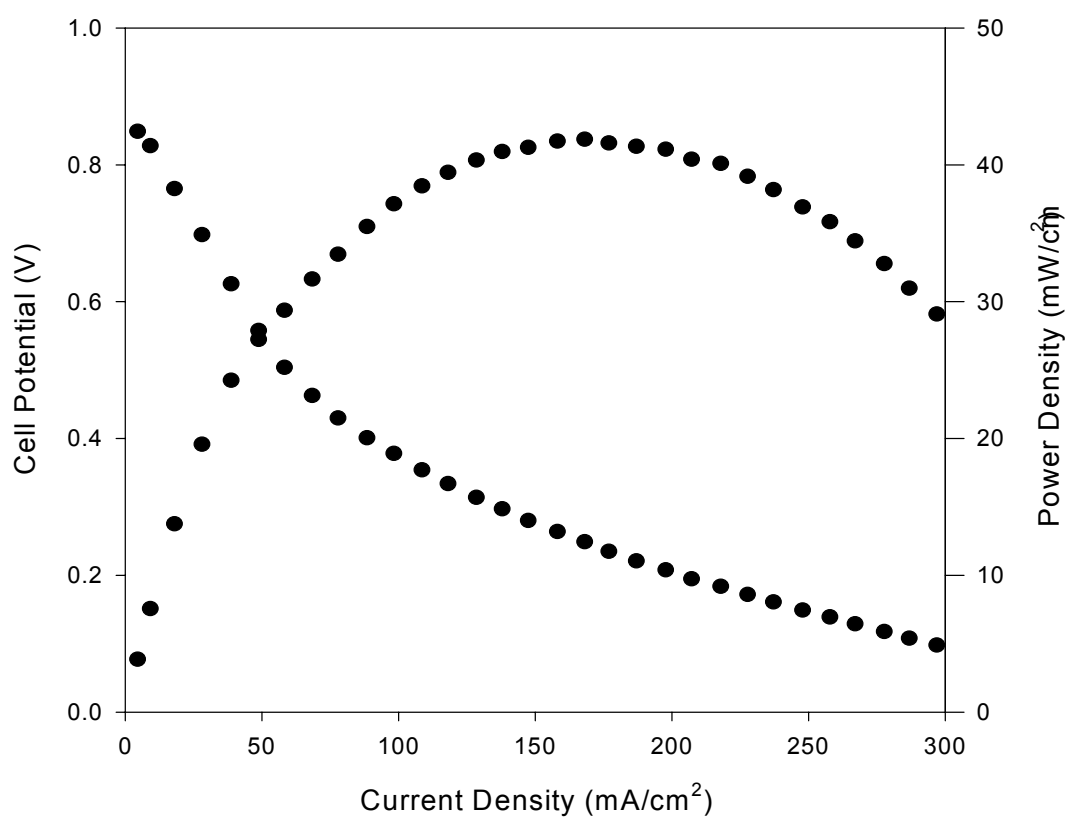

Figure 6.7 IV curve from co-fired LSM/YSZ cell with Ni /YSZ counterelectrode 


\section{LSM / YSZ Fuel Cell Impedance Spectrum}

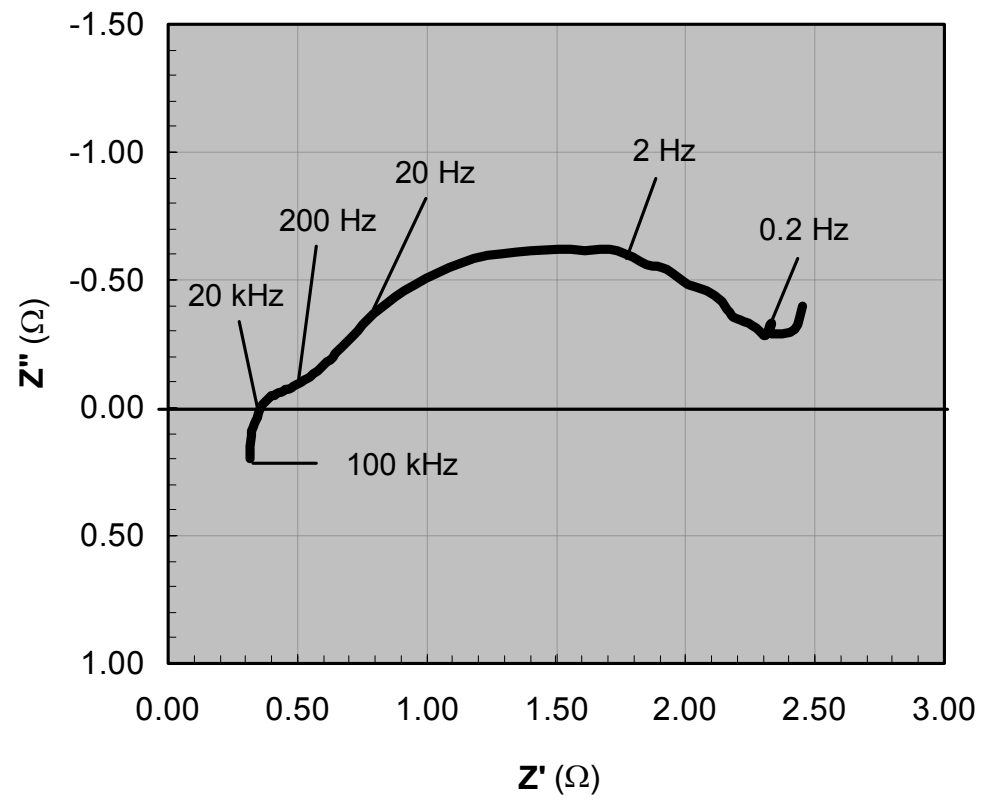

Figure 6.8 Impedance plot from co-fired LSM/YSZ cell

\subsection{Discussion}

It appears that it is possible to produce fuel cells by depositing electrolyte films on LSM substrates via colloidal deposition methods such as vacuum infiltration. The IV curve data exhibit classic fuel cell behavior with some deviations. The open circuit voltage is lower than expected. Based on the Nernst equation (section 1.3), at $800^{\circ} \mathrm{C}$, we expect to obtain an open circuit potential of about 1 volt with these systems. Typical cells deposited on Ni/YSZ substrates commonly achieve open circuit potentials of $1.08 \mathrm{~V}$ at $800^{\circ} \mathrm{C}$. This cell was only able to achieve an open circuit potential of $0.85 \mathrm{~V}$. This low voltage may be due either to a leak in the test rig or microscopic holes in the film. 
Leaks in the test rig could lead to combustion of the hydrogen fuel and/or a lowering of the partial pressure of hydrogen at the anode. Microscopic holes can lead to electronic shorts across the electrolyte - between the current collectors and the conductive electrodes.

The power density is also lower than expected. SOFC's have exhibited power densities of up to $2000 \mathrm{~mW} / \mathrm{cm}^{2}$. Our cell only achieved a power density of $43 \mathrm{~mW} / \mathrm{cm}^{2}$. This low power density is partially a result of the lowered open circuit potential, but the voltage curve also drops rather rapidly as more current is drawn from the cell. While this power density is rather low, the system has yet to be optimized.

The impedance data also exhibit fuel cell behavior. The impedance plot exhibits two semicircles as expected. On the impedance plot, the first semicircle stretches from about $20 \mathrm{kHz}$ to $20 \mathrm{~Hz}$, and the second semicircle stretches from about $20 \mathrm{~Hz}$ to $0.2 \mathrm{~Hz}$. The second semicircle dominates the plot and partially obscures the first semicircle. This is typical of fuel cells with poor electrodes. As the electrode improves (greater catalytic activity, increased gas flow), the second semicircle shrinks and the first semicircle is easier to distinguish.

On the impedance plot, the first intercept with the x-axis occurs at $0.35 \Omega$, which is reasonable for a cell of this type. Based on a $1 \mathrm{~cm}^{2}$ test area, a film thickness of 15 $\mu \mathrm{m}$, and a resistivity of $27 \Omega \cdot \mathrm{cm}$ for $\mathrm{YSZ}$ at $800^{\circ} \mathrm{C}$, we expect the resistance of the film alone to be about $0.04 \Omega .{ }^{6.5}$ The additional resistance most likely occurs at the film/substrate interface and through the electrodes. We notice that the impedance curve is in the lower region at high frequencies. This behavior is generally attributed to inductance effects from the platinum wires leading up to the current collectors on the cell. 
When done correctly, impedance spectroscopy can provide data concerning the affects of variables such as electrode thickness, surface area, and impurities. ${ }^{6.6}$ Impedance spectroscopy has also been used to develop optimum electrode microstructures for mixed electrodes. ${ }^{6.7,6.8}$ The current interrupt data can be used as a check on the impedance data and as an input to aid in the development of an equivalent circuit for the impedance plot. A new equivalent circuit was not formulated as part of this work.

In most impedance analysis of working electrodes, a reference electrode is used to separate the impedance contributions from the electrolyte and the counterelectrode. We did not choose to use a reference electrode in these experiments. Correct use of the reference electrode entails adherence to stringent geometric and electrical requirements. ${ }^{6.9}$ First of all, it is important that the reference electrode have a very low impedance. Large impedance contributions from the reference electrode can lead to large errors in the spectra obtained . $^{6.10,6.11}$ Secondly, it has been shown that different equipotential surfaces are sampled by the reference electrode as the frequency is varied in thin films. ${ }^{6.12}$ This makes thin film measurements subject to large errors.

The position of the reference electrode can also have large effects on the accuracy of the data obtained. It has been found both theoretically and experimentally that the reference electrode must be placed a minimum distance away from the working electrode. $^{6.13}$ This generally corresponds to at least one electrolyte thickness ${ }^{\cdot 6.14,6.15}$ For a symmetric cell geometry, the positioning of the working and counter electrodes can also lead to errors in measurement. It has been found that in asymmetric geometries such as ours, the reference electrode does not sample the potential half way through the 
electrolyte as we might expect for symmetric cells. ${ }^{6.12}$ In reality the reference electrode may be sampling potentials closer to the working electrode or even into the bulk of the working electrode. Where exactly is being measured can also change as the frequency of the signal is changed.

In our measurements, we observe very small ohmic resistances and a reasonably small overall resistance. This implies that the film is making excellent contact with the electrode substrate. We cannot rule out the presence of reaction layers, but any layers present do not appear to be impacting cell performance. While these data are limited, from other work done in our group, it appears that the high firing temperatures lead to very low interface impedances. The bulk of the impedance appears to be related to the electrode kinetics.

\section{References}

[6.1] Bard, A. J., and Faulkner, L. R., Electrochemical Methods, John Wiley and Sons, New York, (1980). Ch. 9.

[6.2] Minh, N. Q. and Takahashi, T., Science and Technology of Ceramic Fuel Cells. Elsevier Science. 1995.

[6.3] Brett, C. M. A., and Brett, A. M. O., Electrochemistry: Principles, Methods, and Applications, Oxford University Press (1993) ch.11.

[6.4] Gellings, P. J., and Bouwmeester, H. J. M. eds., The CRC Handbook of Solid State Electrochemistry, CRC Press, Boca Raton, (1997) ch. 8, Electrodics.

[6.5] Arachi, Y., Sakai, H., Yamamoto, O., Takeda, Y., and Imanishai, N., Electrical conductivity of the $\mathrm{ZrO}_{2}-\mathrm{Ln}_{2} \mathrm{O}_{3}(\mathrm{Ln}=$ lanthanides) system, Solid State Ionics, 121 133139 (1999).

[6.6] Juhl, M., Primdahl, S., and Mogensen, M. Characterization of Composite SOFC Cathodes by Impedance Spectroscopy. Proceedings of the $17^{\text {th }}$ Riso International Symposium on Materials Science: High Temperature Electrochemistry: Ceramics and Metals. Poulsen et al, eds. 1996 pp. 295-300. 
[6.7] Van Berkel, F. P. F., van Heuveln, F. H., and Huijsmans, J. P. P. (1994) Characterization of solid oxide fuel cell electrodes by impedance spectroscopy and I-V characteristics. Solid State Ionics, 72, 563-588.

[6.8] Godickemeier, M.; Sasaki, K.; Gauckler, L. J.; Riess, I. Electrochemical characteristics of cathodes in solid oxide fuel cells based on ceria electrolytes. J. Electro. Soc., vol.144, (no.5), 1997. p.1635-46.

[6.9] Primdahl, S., and Hendriksen, P. Pitfalls in Solid Electrode Characterization. Proceedings of the $17^{\text {th }}$ Riso International Symposium on Materials Science: High Temperature Electrochemistry: Ceramics and Metals. Poulsen et al, eds. 1996 pp 403-10.

[6.10] Hsieh, G.; Ford, S. J.; Mason, T. O.; Pederson, L. R. Experimental limitations in impedance spectroscopy. Pt. 1. Simulation of reference electrode artifacts in three-point measurements. Solid State Ionics, Diffusion Reactions, vol.91, (no.3-4), Elsevier, Oct. 1996. p.191-201.

[6.11] Hsieh, G.; Mason, T. O.; Pederson, L. R. Experimental limitations in impedance spectroscopy. Pt. 2. Electrode artifacts in three-point measurements on Pt/YSZ. Solid State Ionics, Diffusion \& Reactions, vol.91, (no.3-4), Elsevier, Oct. 1996. p.203-12.

[6.12] Winkler, J., Hendriksen, N., Bonanos, N., and Mogensen, M. Geometric Requirements of Solid Electrolyte Cells with a Reference Electrode. J. Elec. Soc. 145 [4] 1184-92 (1998).

[6.13] Nagata, M.; Itoh, Y.; Iwahara, H. Dependence of observed overvoltages on the positioning of the reference electrode on the solid electrolyte. Solid State Ionics, Diffusion \& Reactions, vol.67, (no.3-4), Jan. 1994. p.215-24.

[6.14] Hsieh, G.; Mason, T. O.; Garboczi, E. J.; Pederson, L. R. Experimental limitations in impedance spectroscopy. Pt. III. Effect of reference electrode geometry/position. Solid State Ionics, Diffusion \& Reactions, vol.96, (no.3-4), Elsevier, April 1997. p.153-72.

[6.15] Hsieh, G.; Ford, S. J.; Mason, T. O.; Pederson, L. R. Experimental limitations in impedance spectroscopy. Pt. VI. Four-point measurements of solid materials systems. Solid State Ionics, Diffusion \& Reactions, vol.100, (no.3-4), Elsevier, Oct. 1997. p.297311. 


\section{Conclusions}

\subsection{The importance of an integrated approach}

During the course of this research, much progress was made. A method for applying crack-free YSZ films from colloidal suspension was developed. The critical cracking thickness for drying and the effects of additives on particle packing and sintering were studied. A density effect was explored, and $\mathrm{MnO}$ was identified as a sintering additive in constrained systems. A fuel cell was constructed on a co-fired substrate via vacuum infiltration, and electrochemical tests were done.

While the problems with the fabrication of dense ceramic films can be broken down into several categories, it appears that the problem cannot be solved without taking an integrated approach. When developing a fabrication technique, we cannot optimize one property of the film and expect the other properties of the film to remain unchanged. For example, switching to a solvent with lower surface tension (e.g. isopropanol) may fix drying cracks but appears to lead to unacceptable green densities. Any factors that affect device performance must also be examined.

The fabrication methods utilized to produce thin ceramic membranes for fuel cells can also be used to produce electrolytic gas separation devices and ceramic coatings. Electrolytic oxygen separation devices are constructed in a similar manner to fuel cells, in many cases utilizing the same materials. Fuel cells utilize the transport of a gas species 
through an electrolyte to produce electric current while gas separation membranes utilize an electric current to transport a gas species through an electrolyte. Ceramic coatings are another large market where cheap fabrication methods might be useful.

\subsection{The next step}

The factor that has been ignored in this work is the effect of the substrate on the generation of flaws in the film. It is very likely that flaws in the substrate can be directly correlated with flaws in the film. If flaws in the substrate can be eliminated or somehow compensated for, there appears to be no fundamental reason why it should be impossible to produce crack free films on rigid porous substrates under the appropriate fabrication conditions. 